\title{
CONCEPTUALIZATION, THERMAL ANALYSIS, AND MANUFACTURING OF NANO- TEXTURED MICRO-STRUCTURED SURFACES FOR ENHANCED CONDENSATION HEAT TRANSFER
}

\author{
Mete Budakli ${ }^{*}$
}

\begin{abstract}
In the present study, nano-micro-structured surfaces have been systematically designed and manufactured in order to generate controlled dropwise condensation mode for enhanced heat transfer during phase-change from vapor to liquid. The conceptualization of micro-structures was conducted by using thermal modelling of an individual droplet pinned at a single micro-hexagonal cavity. By varying droplet radius, resulting contact angles and geometric dimensions of micro-structure, threshold values have been determined for the later manufacturing process. According to the calculations for instance at contact angles of $150^{\circ}$, a subcooling of $1 \mathrm{~K}$ and a maximum droplet radius of $100 \mu \mathrm{m}$, the edge length and the depth of the micro-structures should be kept below $50 \mu \mathrm{m}$ and $25 \mu \mathrm{m}$, respectively. Ensuring these parameters, a roughly $100 \%$ larger heat transfer coefficient would result compared to that predicted by the classical Nusselt theory for filmwise condensation. Taking into account the mathematical analysis, laser ablation technique was adopted on 7075 aluminum samples to emboss hexagonal structures with respect to the predicted dimensions. After this step, the samples were electrochemically etched in order to achieve contact angles of more than $150^{\circ}$ to ensure superhydrophobic solid-liquid interaction at the surface. Measurements with a high-precision microscope show that most of the structure dimensions and geometric shape were precisely manufactured. The Tensiometer results disclosed that the surface topography at all samples exhibit contact angles larger than $150^{\circ}$ for a sessile droplet with a radius of $100 \mu \mathrm{m}$ pinned on an individual micro-hexagon.
\end{abstract}

Keywords: Micro-structured Surfaces, Dropwise Condensation, Heat Transfer, Thermal Modelling

\section{INTRODUCTION}

Nowadays, engineers are confronted especially with the challenge to design systems which are, on the one side, built by small and complex parts while on the other side they should ensure gradually increasing performance and at the same time making sure that high heat fluxes of critical components are dissipated. In order to manage the latter requirement, generally classical solutions are used consisting a heat sink-fan configuration. Through this configuration the cooling is induced by means of single-phase forced convection and hence the temperature of the component is kept below a critical value at which the failure of the part can take place. The generation of waste heat per unit area (heat flux) has been increased in the past decades though, conventional thermal management systems working with the principle of heat conduction and/or natural or forced convection come up against their limits such as heat transfer performance as well as their relatively invariable assembly design. Thus, it can happen that in the case of insufficient removal of locally generated heat at high temperatures, a considerable destruction of the system can be caused, which calls e.g. the reliability of high-performing components into question. With regard to coping with high heat flux densities, prognoses indicate that the dissipated heat flux will probably exceed $1 \mathrm{~kW} / \mathrm{cm}^{2}$. This above all for those in telecommunications technologies, electric vehicles, avionics systems, high-performance computers or LED-Electronics used in lighting systems is a major issue that limits performance as well as energy efficiency [1]. In order to guarantee a perfect operation of high-performance systems, thermal management systems are gradually being used, which are designed as spray cooling or boiling chambers and thereby use the effect of latent heat to cool components that can reach very high temperatures or work in an environment with increased temperatures. Although these methods are This paper was recommended for publication in revised form by Regional Editor Muslum Arici

${ }^{1}$ Ozyegin University, Faculty of Engineering, EVATEG Center, Nisantepe Mah., Orman Sk. No.13, 34794 Cekmekoy, Istanbul

*E-mail address: mete.budakli@ozyegin.edu.tr

Orcid id: 0000-0003-1721-1245

Manuscript Received 25 February 2021, Accepted 21 April 2021 
advantageous from the point of view of cooling performance, they cannot be flexibly installed in narrow, multi-layered/multi-part systems. In addition, auxiliary devices (pump, liquid reservoir, heat exchanger, etc.) are necessary for their operation, which may have to be serviced at certain intervals, take up space or, in the field of lightweight construction, their own weight must be taken into account. Therefore, the trend has developed into the use of so-called heat pipes. These also work with the principle of the liquid-vapor/vapor-liquid phase change and at the same time can be installed in complicated spaces [2]. Several scientific papers have shown that heat pipes have great potential with regard to the dissipation of increased heat flux densities [3-5]. From the thermodynamic perspective, a heat pipe is viewed as a closed two-phase system whose internal functional principle is based on capillary forces caused by pressure differences without the use of a mechanical pump. Local temperature differences on surfaces/in components can be balanced out in a targeted manner and controlled relatively well. In addition, heat pipes can work almost independently of gravity and are therefore ideal candidates for the cooling of circuit boards or systems that are exposed to varying acceleration forces (aircraft, rotating systems, etc.). In order to cool an object, one of the ends (evaporation area) is brought into contact with the object in question and there the heat is supplied to the working medium (liquid state) located inside the heat pipe. Due to the supplied heat, the working medium changes from the liquid to the vapor state. Then, through the increased pressure (vapor pressure) in the evaporation area, the steam reaches the other end of the pipe (condensation area) via the so-called adiabatic heat transport path (transport area), which is defined as the length between the evaporation and condensation area.

In contact with the environment (e.g. air) at a lower temperature, or immersed in a liquid cooling medium/solid object (heat sink), there is a driving temperature difference between the condensation area and the heat sink. As a result, this causes the condensation of the steam and thus the release of heat (latent heat) to the cooler medium/object. Based on the phase change vapor to liquid, the pressure in the condensation area is lower than in the evaporation area. The condensate is transported to the evaporation area by capillary forces, which are caused either by the use of longitudinal micro-grooves, inserted wire mesh or the use of sintered structures on the inner wall of the heat pipe. The heat transport within the heat pipe is basically determined by the viscosity of the working medium, the steam/sound speed, liquid-steam interaction, boiling in the evaporation area and by the capillary forces at the liquidwall interface (micro-structures, inserts, etc.). Particularly in the condensation area - depending on the operating point and the surface wetting properties - a rather complicated vapor-liquid-wall interaction occurs in the form of film and/or droplet condensation. The process condition of the latter can have a decisive influence on the overall performance of the heat pipe. This phase-change phenomenon not only plays an important role in heat pipes, it is also essential for the function of various technologies such as heat exchangers [6] or systems used in energy generation $[7,8]$ or in cryogenics. During the condensation process, the vapor phase faces a subcooled wall under saturated conditions, on which the phase-change occurs through the activation of local nuclei [9]. Mostly the nucleation process can be promoted by two main reasons. The first can be the presence of nano-micro impurities existing on the surface, which act as initiator for the formation of liquid mass. The second one can be a local increase in vapor condensation due to potential or pressure differences close to the vapor-solid interface. However, the identification and differentiation between both the mechanisms is rather sophisticated and can only be reconstructed by using molecular dynamics simulations. From the engineering point of view, this process is rather defined and determined by the difference between wall temperature and steam temperature, which is the driving force that causes the transition from steam into liquid form through phasechange and at the same time releases latent heat [10]. Factors such as operating temperature, pressure or thermopyhsical fluid properties can significantly influence the overall process $[11,12]$. The interaction on the wall surface begins with the formation of growing droplets, which then coalesce with neighboring droplets which then wet the surface completely as a film (see Figure 1a) or partially wetting through droplets occurs (see Figure 1b). 
a)

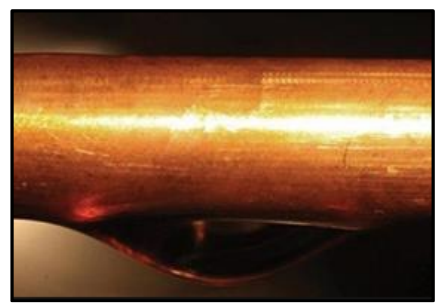

b)

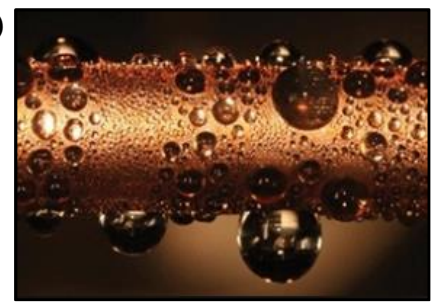

Figure 1. Condensation on the surface of a subcooled copper pipe: a) film condensation, b) droplet condensation [9]

The type of wetting of the wall surface is microscopically dependent on the surface properties. In detail (see Figure 2), however, it is dominated by the surface tension of the liquid, the surface free energy of the non-wetted solid and the interfacial energy at the solid-liquid phase boundary [13]. Film condensation occurs when there is a high surface free energy of the wetted wall [14] and the associated relatively strong surface wetting (hydrophilicity) occurs.

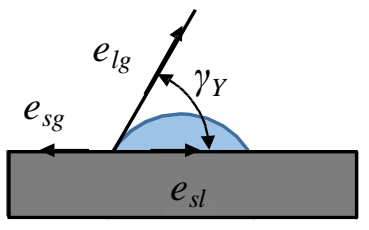

$e_{s g}=e_{s l}+e_{l g} \cos \left(\gamma_{Y}\right)$ [Young equation]

$\gamma_{Y}:$ Young contact angle

$e_{s g}:$ Surface energy at the interface solid-gas

$e_{s l}: \quad$ Surface energy at the interface solid-liquid

$e_{l g}:$ Surface energy at the interface liquid-gas

Figure 2. Equation for surface energy and contact angle according to Young law

Compared to this, droplet condensation can occur on walls with a rather low surface free energy, i.e. can be observed with relatively poor surface wetting (hydrophobicity), which means that the liquid droplets only adhere to the surface at certain points and are then "repelled" by it [15]. The surface wettability is generally assessed by measuring the contact angle, which is defined between the solid-liquid and liquid-gas phase interfaces (see Figure 3). It is reported in the literature that higher heat transfer coefficients or heat flux densities are more likely with condensation on (super-)hydrophobic surfaces. Associated with this, the state of droplet condensation can be achieved by modifying the condensation surface or by choosing a suitable working medium with strong surface tension. In one study, e.g. metal surfaces are shot at with a controlled ion beam with the aim of providing nano-structuring on the surface [16].

a)

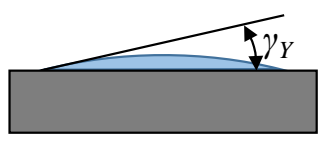

$\gamma_{Y}<5^{\circ}$, after $5 \mathrm{sec}$. b)

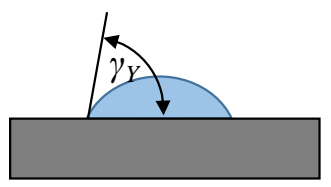

$\gamma_{Y}<90^{\circ}$ c)

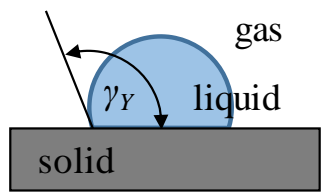

$\gamma_{Y}=90^{\circ}-150^{\circ}$ d)

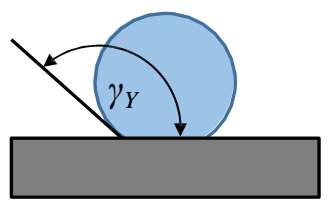

$\gamma_{Y}=150^{\circ}-180^{\circ}$

Figure 3. Behavior of a drop on surfaces with different wetting properties: a) superhydrophilic, b) hydrophilic, c) hydrophobic, d) superhydrophobic

In the subsequent experiments of the same study it was shown that an intensification of the drop condensation could be achieved. However, this technique is reported to be relatively complex, expensive, and difficult to apply as large scale surface modifications. Similarly in another investigation, aluminum alloy samples having unprocessed, polished, and laser-pulsed surfaces were used to explore the interaction of water droplets on the samples [17], but for the evaporation purpose. Empirical correlations were developed by using wetting properties, surface roughness, and 
surface free energy and experimental parameters of the droplet. In addition, the use of micro-needles/-pins or -grooves can promote the increased formation of droplets with a larger contact angle and thus the heat transfer of the condensation process can be improved [18]. For this purpose, the geometry and shape of the micro-structures must be appropriately selected such that an optimal fluid-wall interaction can be achieved [5]. As an example, for this purpose, some researchers have carried out a numerical study in order to investigate the effect of semi-conical and semi-pyramidal geometries on the heat transfer in dropwise condensation mode [19]. Therefore, the height of structures, their roughness ratio, solid fraction, and basal area have been varied and their impact on single droplet and overall heat transfer have been evaluated. The authors reported that dropwise condensation enhancement of 3.5 times was achieved for the case when the structure height decreased by approximately 16 times. Furthermore, another group of scientists used thornlike geometries bi-philic (hydrophobic and hydrophilic) surface topography to promote liquid efflux behavior [20]. The thorn-like surface structure were manufactured by screen printing. A more sophisticated novel concept of structures was used in a further study by using so-called Janus-mushroom structure exhibiting which have shown a rather superhydrophobic liquid behavior for water [21]. In addition to the mechanical change in the surface topography, the surface tension of the liquid plays a fundamental role in droplet condensation, as it is an essential thermopyhsical parameter not only with regard to the local spread of individual droplets but also can determine the onset of droplet coalescence [22]. By using organic/inorganic compounds [23], polymers [24] or Teflon coatings [25,26], the drop repulsion (dynamic hydrophobicity) of surfaces can be increased [27]. It was already reported in [28] that fluorinated compounds have a low surface energy and are therefore able to reduce the interface energy, which in turn supports the formation of droplets with large contact angles. In some studies, small amounts of fluorinated solution were used as a mixture for the production of hydrophobic surfaces [29].

Compared to the surface modifications that require a mechanical manufacturing method, coatings are relatively inexpensive and can be made by simply dipping, spraying, or steaming. One possible way to obtain superhydrophobic copper surfaces for instance having a maximum contact angle of $168^{\circ}$ can be achieved by the so-called thermo solution immersion technique [30]. As solution, ethanol and tetradecanoic acid is used, while a heat treatment at $45^{\circ} \mathrm{C}$ for about 4 hours is necessary. The copper surface can have a sliding contact angle of less than $3^{\circ}$ for water. However, when selecting the coating material with regard to its use in condensation processes, factors such as compatibility with the base material, solubility in the working medium, coefficient of linear expansion, layer thickness and, in particular, thermal conductivity must be taken into account. In view of the literature research, it can be summarized that several experimental and numerical work has been carried out on the subject of condensation as a contribution to improving heat transfer. Various correlations have been developed for determining the heat transfer coefficient during condensation on substrate surfaces with (super-)hydrophobic properties, or methods for producing optimal surface properties for the intensification of droplet condensation under several operating conditions have been proposed for different working fluids. However, most of the studies were generally only focused on realizing surface properties with only one method or for a specific working medium and operating range, and thereby achieving an improved thermo-fluiddynamic transport process. In other studies, scientists dealt with the manufacturing method of photolithography or investigated the use and effect of carbon nano-tubes with regard to the creation of hydrophobic surfaces [31,32]. In addition, substrates were coated with wax or treated with galvanic deposition and only their influence on surface wetting, thermomechanical stability and chemical resistance was investigated. In some studies, micro-milled surface structures were even used in condensation experiments; in other scientific projects, however, copper surfaces were treated electrochemically and thus large heat transfer coefficients were achieved [33]. However, only small number of information is available about their influence on locally generated nucleation activation, their use at higher operating pressures and their utilization with different working media. Furthermore, few studies have been carried out on the subject of condensation of superheated steam. Most of these included the condensation of superheated refrigerants (e.g. R134a, $\mathrm{R} 744, \mathrm{R} 410 \mathrm{~A}$ ) on pipe surfaces [34]. Some investigations on this topic have only been done with the use of numerical calculations [35]. Although a large number of scientific work has been carried out to improve the heat transfer during condensation, there are still open questions about the understanding of the thermo-fluid dynamic transport mechanisms during the phase-change on different surface topographies.

The main content in this work was focused on the systematic and specific conceptualization of an appropriate 
surface topography which should be realized on several subcooled aluminum (Al) substrates in order to achieve enhanced phase-change heat transfer in dropwise condensation mode. By adopting heat transfer calculations on a single condensing droplet as a model, characteristic dimensions of the micro-structure were determined and later manufactured with the help of the laser manufacturing technology and electrochemical etching technique. As microstructure geometry, a hexagonal shape was selected due to the fact that in the study of Chen and Sun [36] it has been shown that liquids existing on hexagonal structured surfaces can show strong superhydrophobic behavior and are therefore a promising geometry for heat transfer improvement. Another reason for the selection of hexagonal geometry was to achieve the largest use of area. Thereby the key focus was on achieving significant improvements in heat dissipation as well as efficient use of surface area. At the same time, it was taken into account that compared to non-modified surfaces, an increase in heat dissipation should be obtained under equivalent operating conditions. Furthermore, as a lower threshold for design bases in heat transfer performance, heat transfer coefficient according to classical Nusselt theory approach has been considered. In addition, a parametric study on governing influencing factors such as contact angle, geometric dimensions of micro-structure, and thermal resistances have been carried out in terms of determination of minimum and maximum influencing values for the entire condensation process. Finally, after sample fabrication, contact angle measurements have been carried by using sessile droplet method in order to validate the predicted values calculated through heat transfer modelling.

\section{MATHEMATICAL MODELLING}

Generally, in most of the studies [17,19] a subcooled vertically aligned plate (copper, aluminum etc.) is used for the experimental investigation of the condensation process as presented in Figure 4. The subcooling is generated through a cooling liquid circulated at the back of the substrate such that the so-called driving temperature difference can be set. In order to determine the heat flow rate $\boldsymbol{Q}_{\boldsymbol{P}}$ extracted during the phase-change from vapor to liquid, the Newton's law [37] of cooling can be utilized (see Equation 1).

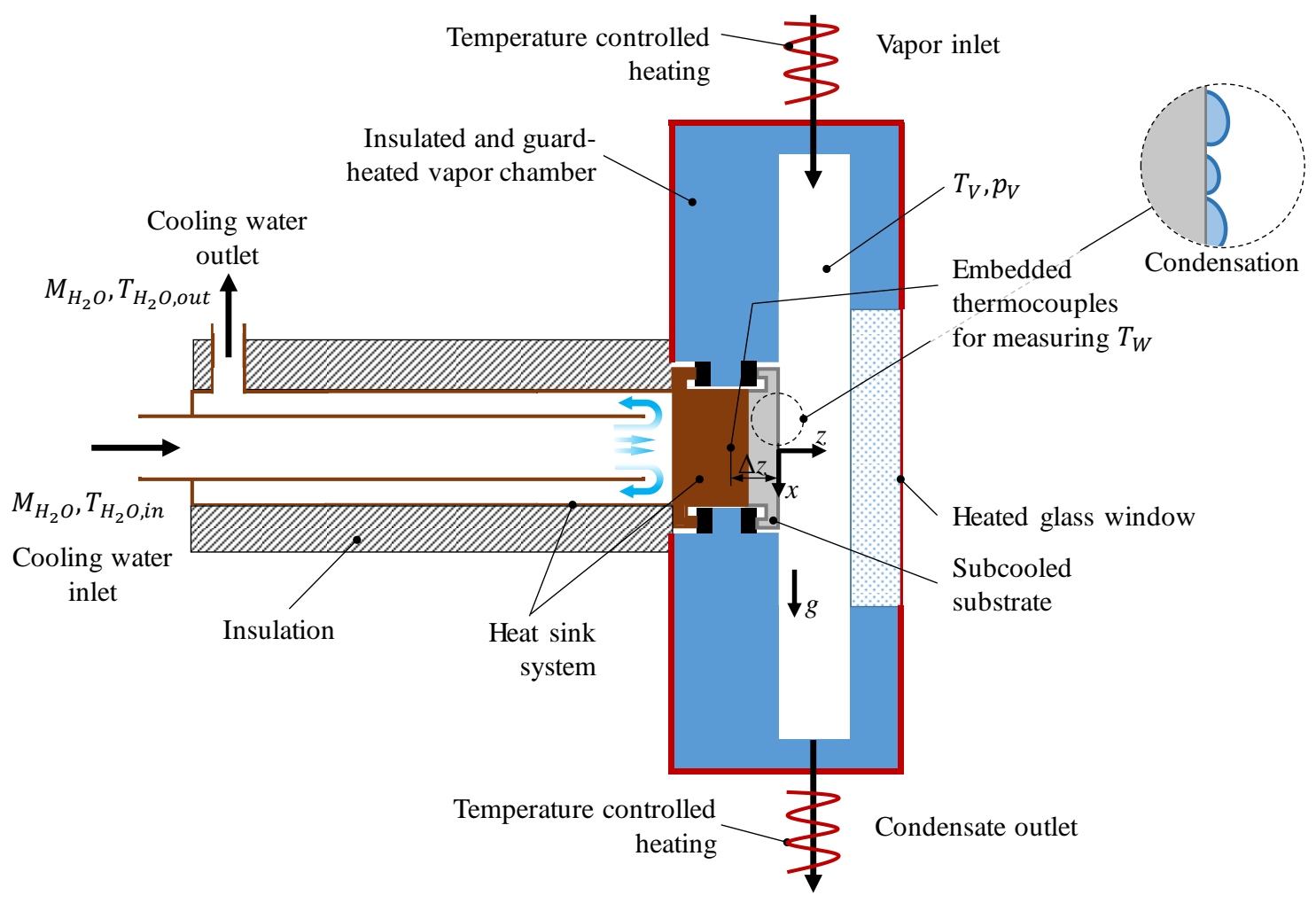

Figure 4. Simplified sketch of a chamber for a vapor condensation investigation 
The surface temperature $\boldsymbol{T}_{\boldsymbol{S}}$ results with the assumption of one-dimensional heat conduction according to Fourier's law [37] through the distance $\Delta \boldsymbol{z}$, the thermal conductivity $\lambda_{\boldsymbol{P}}$ of the material used for the plate and the surface area $\boldsymbol{A}_{\boldsymbol{P}}$ as described with Equation 2.

$$
\begin{gathered}
Q_{P}=M_{\mathrm{H}_{2} \mathrm{O}} C_{\mathrm{H}_{2} \mathrm{O}}\left(T_{\mathrm{H}_{2} \mathrm{O}, \mathrm{out}}-T_{\mathrm{H}_{2} \mathrm{O}, \text { in }}\right) \\
T_{S}=\frac{Q_{P} \Delta z}{\lambda_{P} A_{P}}+T_{W}
\end{gathered}
$$

Then, the heat transfer coefficient $\alpha$ can be calculated with

$$
\alpha=\frac{Q_{P}}{A_{P}\left(T_{V}-T_{S}\right)}
$$

With the above given approach, the condensation heat transfer coefficient can be determined for the phasechange on the entire surface area. However, the mode of condensation cannot be directly identified. For the latter purpose, the well-known approach of Wilhelm Nusselt [38], the so-called Nusselt theory for filmwise condensation (FWC) can be used in order to identify the mode of condensation. Assuming a plate length of $x=1 \mathrm{~m}$, the overall heat transfer coefficient determined by the Nusselt theory can be calculated with

$$
\alpha=\frac{4}{3}\left[\frac{\rho_{L}\left(\rho_{L}-\rho_{V}\right) g \Delta h_{e v} \lambda_{L}^{3}}{4 \mu_{L}\left(T_{V}-T_{S}\right)} \frac{1}{x}\right]^{\frac{1}{4}}
$$

Here the liquid thermal conductivity $\lambda_{L}$ and the densities for liquid and vapor have been considered to be $0.677 \mathrm{~W} / \mathrm{mK}, 961.9 \mathrm{~kg} / \mathrm{m}^{3}$, and $0.598 \mathrm{~kg} / \mathrm{m}^{3}$.

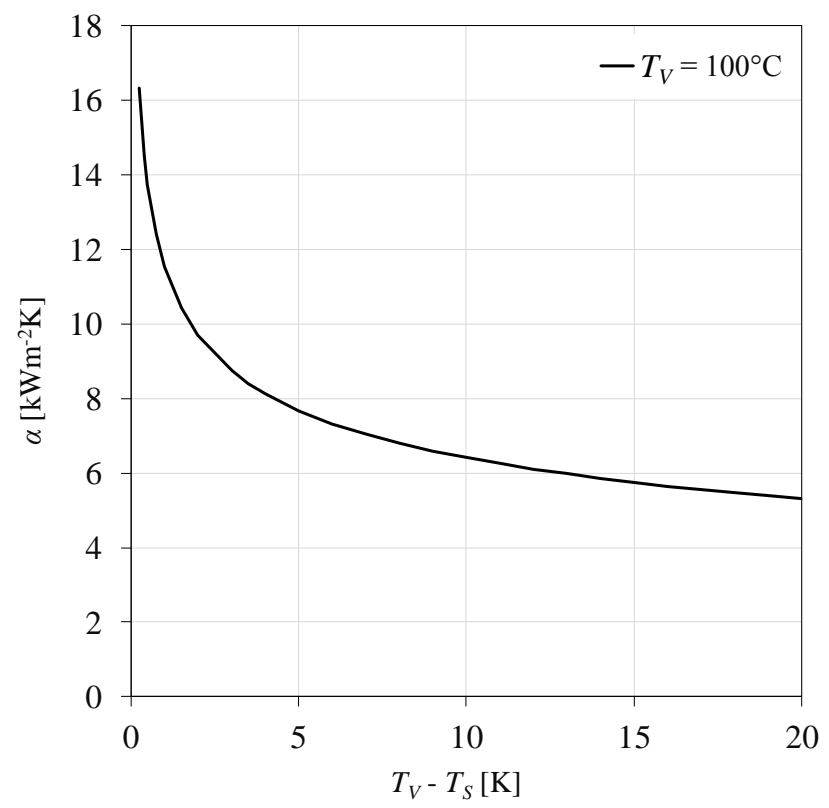

Figure 5. Overall heat transfer coefficient for a surface area of $1 \mathrm{~m}^{2}$ for varying subcooling temperature according to the Nusselt theory [38] 
The results for heat transfer coefficient calculation for the subcooling temperature $\boldsymbol{T}_{\boldsymbol{V}}-\boldsymbol{T}_{\boldsymbol{S}}$ ranging up to $20 \mathrm{~K}$ is illustrated in Figure 5. All thermopyhsical properties are considered based on the bulk mean temperature 0.5 $\left(\boldsymbol{T}_{\boldsymbol{V}}+\boldsymbol{T}_{\boldsymbol{S}}\right)$. At the saturation condition $100^{\circ} \mathrm{C}$, the heat transfer coefficient decreases with increasing subcooling temperature, since the thickness of condensed liquid film leads to a larger thermal resistance. When higher saturation temperature for vapor is assumed, a minor increase in heat transfer performance is predicted by the Nusselt theory for comparable subcooling temperature. This is mostly attributed to the larger driving temperature difference between the surface of the wall and the vapor [30].

As mentioned in the introduction section, engineers are focused on designing thermal devices for condensation in a way that large amount of heat can be transported at similar subcooling temperature [1,2]. For instance, instead of running a heat exchanger in the FWC mode, achieving dropwise condensation (DWC) mode yields a higher heat transfer performance at comparable operating conditions. To obtain the latter mode, variation of governing parameters such as operating temperature/pressure, fluid thermopyhsical properties (surface tension, density, viscosity), number of active cavities/nucleate sites [10], droplet size [39-41], and wettability character of the surface [14] is crucial. Concerning the wetting mechanism, several methods like sandblasting [42,43], use of micro-obstacles or micro-grooves [5], application of argon ion-beam irradiation [44], use of organic or inorganic compounds [23,45], polymers [46], and various other coatings [47] can be utilized in order to manipulate the surface towards strong de-wetting, i.e. (super)hydrophobicity. Up to now, single methods have been used for surface modification in most of the cases, while only less number of studies were concentrated on using combined techniques to modify surface properties [48,49]. As described previously, in this study the aim is to conceptualize a surface by selectively changing the surface topography such that the number of condensing single droplets can be controlled and hence the heat transfer rate can be augmented. Nevertheless, to fabricate the desired surface texture with the purpose of controlled liquid-wall interaction for practical applications, it is essential that materials and manufacturing techniques should be cheap, time-saving and technically realizable with regard to easy manufactural, reliable and usable at large-scale applications in industry. Besides easy manufacturability and control of number of nucleation sites, high mechanical durability has to be ensured.

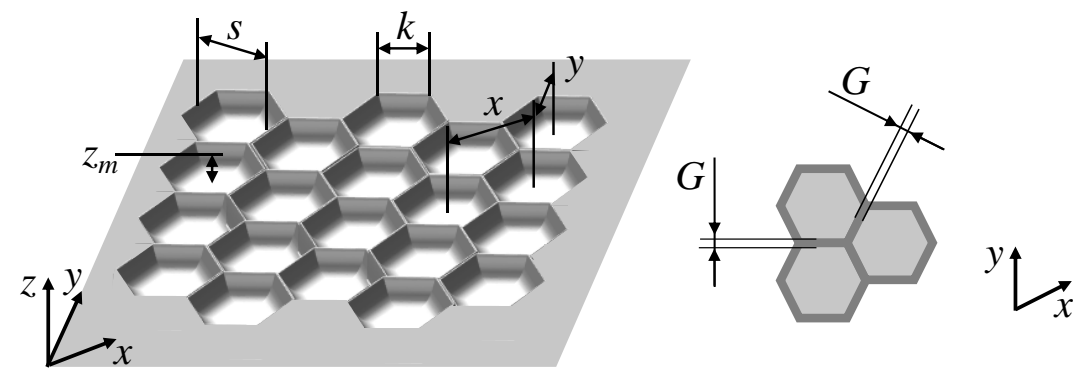

Figure 6. Major geometric parameters of hexagonal structure configured on substrate

In the view of these aspects, various geometrical structures and manufacturing techniques can be adopted. In this study, the goal was to use aluminum material which is cheaper compared to copper and has rather good thermal conductivity for heat transport. The substrates which are going be tested in a later study were treated with laser ablation technique in order to achieve fast replication of surface modification with the target for future application in largescale industrial systems. As previously stated, a hexagonal shape was used, since in the work of Chen and Sun [36] it has been proven that liquids contacting surfaces exhibiting such kind of structures show strong superhydrophobic behavior compared to rectangular or triangular geometries and are consequently a promising candidate for heat transfer enhancement (see Figure 6). Further reason choosing hexagonal shape was that the largest possible use of the area can be ensured with the most possible small distance setting (e.g. $x$ and $y \leq 150 \mu \mathrm{m}$, at constant $k$ and $z m$.). Although the strategy for the surface preparation might sound clear, detailed thermal analysis has been carried out in order to determine minimum/maximum threshold values for the geometric parameters of selective nano-micro-structuring to achieve heat transfer increase. 


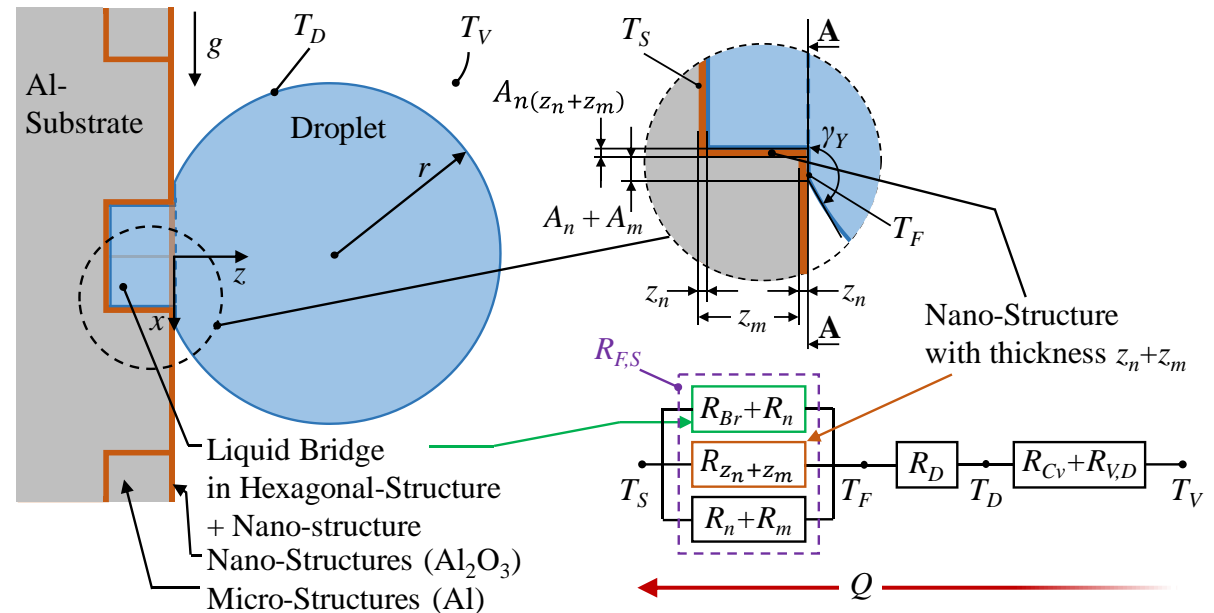

Figure 7. Heat transfer model of a single condensing droplet: left: Single droplet on a hexagon cavity, right: circuit diagram of the heat transfer/thermal resistance

In order to identify the influence of the micro-structuring on the condensation process, the geometric parameters $k, s, z_{m}$, and $x, y$ should be systematically varied. However, to make a preliminary evaluation and predefinition of the size spectrum, a detailed thermal analysis was carried out as follows by using a single condensing droplet pinned on an individual hexagon nucleation cavity as follows. The calculation of the quasi-steady heat flow can be carried out in the first step with the following expression by writing the temperature difference between the vapor phase $\boldsymbol{T}_{\boldsymbol{V}}$ and the substrate surface $\boldsymbol{T}_{\boldsymbol{S}}$ :

$$
\Delta T_{V, S}=\Delta T_{C v}+\Delta T_{V, D}+\Delta T_{D, F}+\Delta T_{F, S}
$$

The above equation describes the temperature profile within a condensing individual droplet, which is the temperature development from the vapor phase to the substrate surface. It can be modelled with the consideration of the heat transfer/thermal conductivity resistances existing at the vapor-droplet interface, within the droplet, and at the interface shaped between the droplet-foot and the substrate surface (nano-structure and micro-structure), see Figure 7. The temperature drop caused by the droplet curvature can be described according to Carey [50] with the following equation:

$$
\Delta T_{C v}=\frac{2 T_{V} \sigma_{D}}{r h_{e v} \rho_{D}}
$$

Here, $\rho_{D}$ and $\sigma_{D}$ are $961.9 \mathrm{~kg} / \mathrm{m}^{3}$ and $0.0756 \mathrm{~N} / \mathrm{m}$. Furthermore, the temperature difference between the vapor at saturated condition $T_{V}$ and liquid droplet interface $T_{D}$ can be given as

$$
\Delta T_{V, D}=\frac{Q}{2 \pi r^{2}\left(1-\cos \left(\gamma_{Y}\right)\right) \cdot \alpha_{V, D}}
$$

while the heat transfer coefficient for condensation at the interface can be according to Schrage [51], and Umur and Griffith [52]:

$$
\alpha_{V, D}=\frac{2 \varepsilon}{2-\varepsilon} \frac{1}{\sqrt{2 \pi R_{V} T_{V}}} \frac{h_{e v}^{2}}{v_{V} T_{V}}
$$


The parameter $\varepsilon$ is called as the condensation factor, while $R_{V}$ has been considered as $461.5 \mathrm{~J} / \mathrm{kgK}$. $\varepsilon$ describes the ratio of vapor molecules that will be captured by the liquid droplet to the total number of vapor molecules reaching the liquid-vapor interface. $\varepsilon$ ranges from 0 to 1 , while in this study 0.1 has been chosen which is a quite realistic value for saturated water vapor at a pressure of 1 bar according to the measured data reported in the work of Rohsenow [53]. The latent heat at the droplet surface released by the vapor is considered as heat conduction through the liquid bulk towards the substrate given by

$$
\Delta T_{D, F}=\frac{Q \gamma_{Y}}{4 \pi r \sin \left(\gamma_{Y}\right) \cdot \lambda_{D}}
$$

The droplet thermal conductivity $\lambda_{D}=0.677 \mathrm{~W} / \mathrm{mK}$ has been used. The temperature decrease $\Delta T_{F, S}$ between the foot of the droplet and the substrate surface due to the nano-micro-structuring can be calculated using a the following expression:

$$
\Delta T_{F, S}=\frac{Q}{\lambda_{n}\left(A_{F}-A_{H e x a(\sqrt{3} k)}\right)\left[\frac{A_{B r\left(\sqrt{3} k-2 z_{n}\right)^{\lambda_{D}}}}{\left(z_{m}+z_{n}\right)\left(A_{F}-A_{H e x a}(\sqrt{3} k) \lambda_{n}+z_{n} \lambda_{D} A_{B r\left(\sqrt{3} k-2 z_{n}\right)}\right.}+\frac{A_{n\left(z_{m}+z_{n}\right)}}{\left(z_{m}+z_{n}\right)\left(A_{F}-A_{H e x a(\sqrt{3} k)}\right)}+\frac{\lambda_{m}}{z_{m} \lambda_{n}+z_{n} \lambda_{m}}\right]}
$$

where the geometric parameters are

$$
s=\sqrt{3} k
$$

and

$$
\begin{gathered}
A_{B r\left(\sqrt{3} k-2 z_{n}\right)}=2 \sqrt{3}\left(\frac{\sqrt{3} k}{2}-z_{n}\right)^{2} \\
A_{F}=\pi r^{2} \sin ^{2}\left(\gamma_{Y}\right) \\
A_{H e x a(\sqrt{3} k)}=A_{B r\left(\sqrt{3} k-2 z_{n}\right)}+A_{n\left(z_{m}+z_{n}\right)}=\frac{\sqrt{3}}{2}(\sqrt{3} k)^{2} \\
A_{n\left(z_{m}+z_{n}\right)}=\frac{1}{2} \sqrt{3}\left[(\sqrt{3} k)^{2}-4\left(\frac{\sqrt{3} k}{2}-z_{n}\right)^{2}\right]
\end{gathered}
$$

It is assumed that $s_{n} \approx z_{n}$. Considering all the temperature drops in a single equation, the individual droplet heat flow rate is

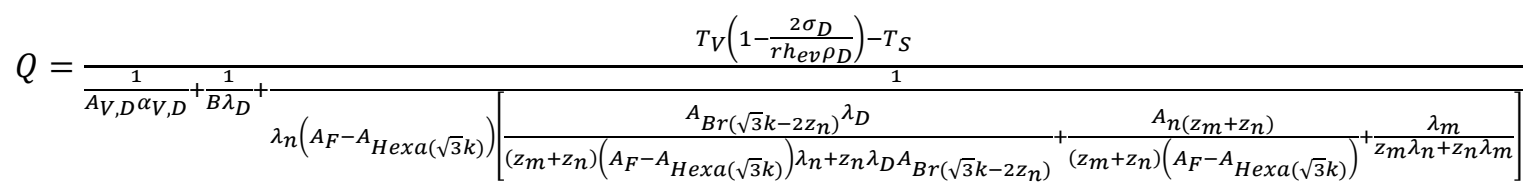

where

$$
A_{V, D}=2 \pi r^{2}\left(1-\cos \left(\gamma_{Y}\right)\right)
$$




$$
B=4 \pi r \sin \left(\gamma_{Y}\right) \gamma_{Y}^{-1}
$$

To note, the above-written equations do not consider the effect of gravitation. In case of vertical alignment of the substrate, the droplets will leave the surface when the gravitational force overcomes the surface tension force as well as the adhesion force at the solid-liquid interface. One can assume that this will increase the frequency of droplet detachment and reinitiating of nucleation sites and hence will contribute to increase in heat transfer performance.

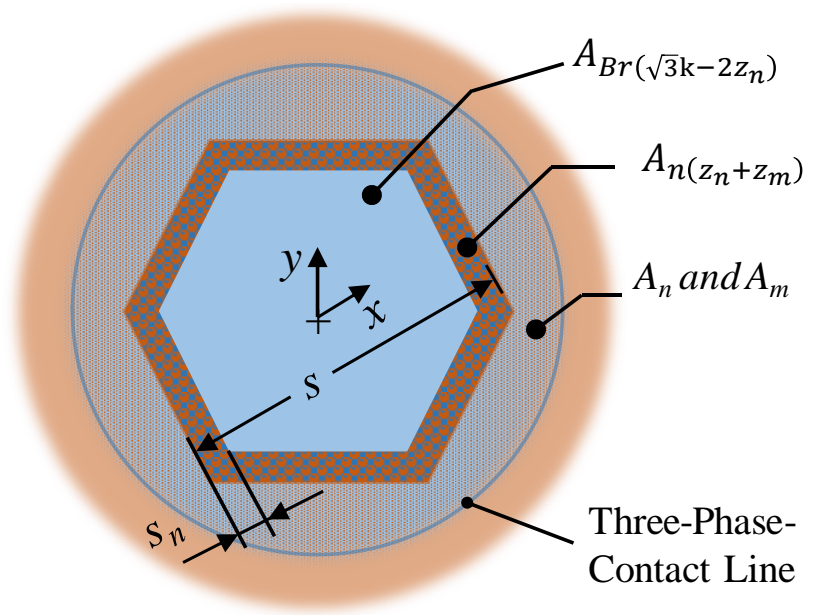

Figure 8. Liquid-wall interaction at the droplet foot at the cutting plane A-A

The interaction of the wall-liquid interfaces at the droplet foot is presented in Figure 8 with the projection created at the section plane A-A. On closer inspection, it can be assumed that the contact angle will change with the droplet radius or with the time-changing increase in mass due to condensation on the droplet skin. It can also be supposed that the heat flow will change as a function of time. Within the scope of this work, the increase in the droplet radius is considered with quasi-steady droplet radii of $r=50 \mu \mathrm{m}, r=75 \mu \mathrm{m}$, and $r=100 \mu \mathrm{m}$. However, depending on the reproductive behavior (pinning or stick-slip), other influencing variables such as surface tension and contact angle (both are temperature-dependent) exist during droplet expansion/contraction. The decisive factor is how the superiority of each individual influencing factor develops (further) to which states and configurations. Therefore, the present study intends to pursue this question through preliminary calculations and to determine the interdependencies of the influencing factors with one another, taking into account varying boundary conditions on the global heat transport of a single droplet.

\section{RESULTS OF THERMAL ANALYSIS}

In Figure 9, the variation of single droplet heat flow rate and heat transfer coefficient depending on the contact angle and three droplet radii $50 \mu \mathrm{m}, 75 \mu \mathrm{m}$, and $100 \mu \mathrm{m}$ are shown, where $T_{V}-T_{S}=1 \mathrm{~K}$. It can be clearly seen that larger droplets have higher heat flow rate, which decreases with increasing contact angle. This might be due to the fact that the overall thermal resistance rises when more liquid mass accumulates on the surface of the droplet by phasechange. For a larger droplet diameter, larger heat flow rate is predicted, which might be a result of increased interfacial area between the vapor and the droplet surface. Similar findings have been seen in the work of Enright et al. [54] and [55], where droplets condensed at sub-atmospheric pressure levels. The values for heat transfer coefficient have been calculated through dividing $Q$ by the area of the droplet foot $A_{F}$ for the corresponding contact angle. For an increasing contact angle, the thermal resistances caused by the liquid mass, curvature and that at the vapor-liquid interface rise. However, the foot area of the droplet decreases for larger contact angle values which leads to a significant increase in heat transfer coefficient. Compared to this, the heat transfer coefficient for a single droplet first decreases when the contact angle starts increasing from $90^{\circ}$ to $120^{\circ}$. However, significant enhancement of heat transfer coefficient results 
for contact angles larger than $150^{\circ}$. The latter value is a threshold where surfaces are defined to be super-repellent. At the same time, the predictions reveal larger heat transfer for small droplets which indicate that decreasing droplet foot diameter at large contact angles can intensify the overall heat transfer performance.

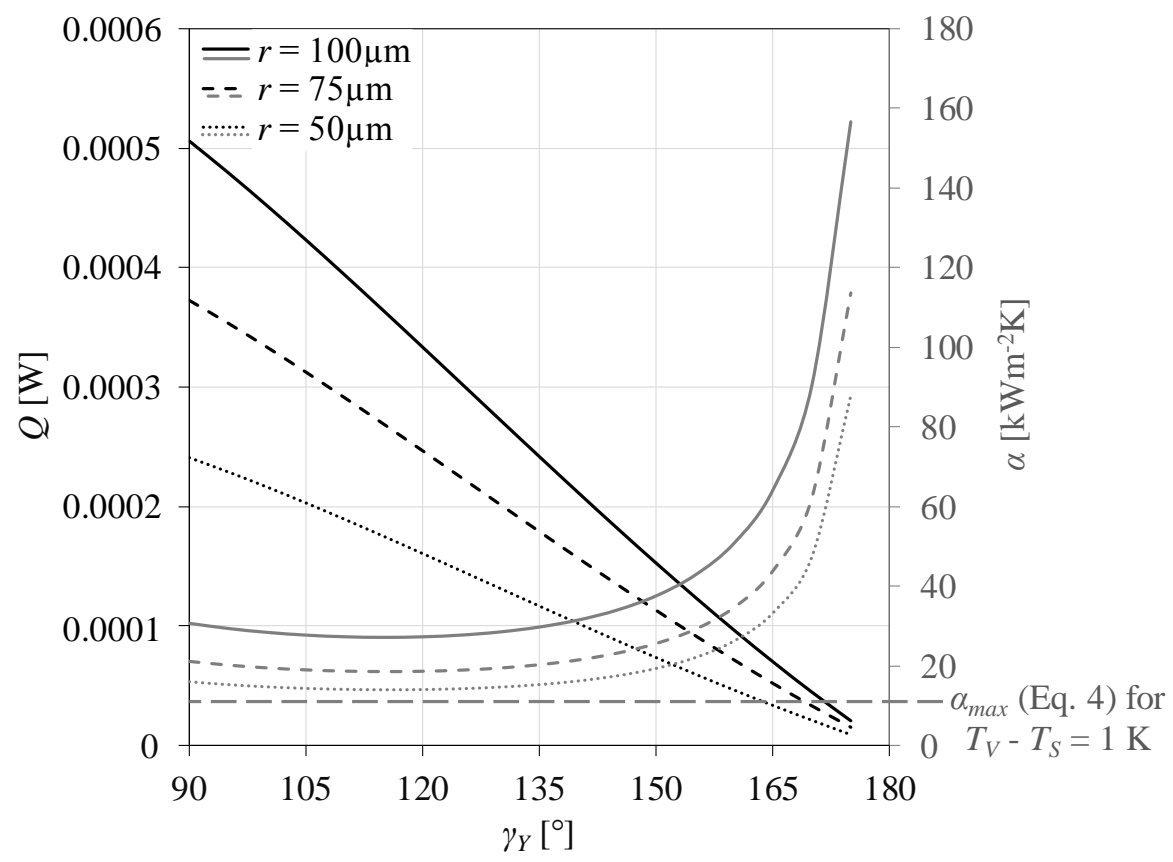

Figure 9. Heat flow rate $Q$ and overall heat transfer coefficient $\alpha$ for various contact angle $\gamma_{Y}$ and droplet radius $r$ with comparison of maximum heat transfer coefficient according to Equation 4 for $T_{V}-T_{S}=1 \mathrm{~K}$

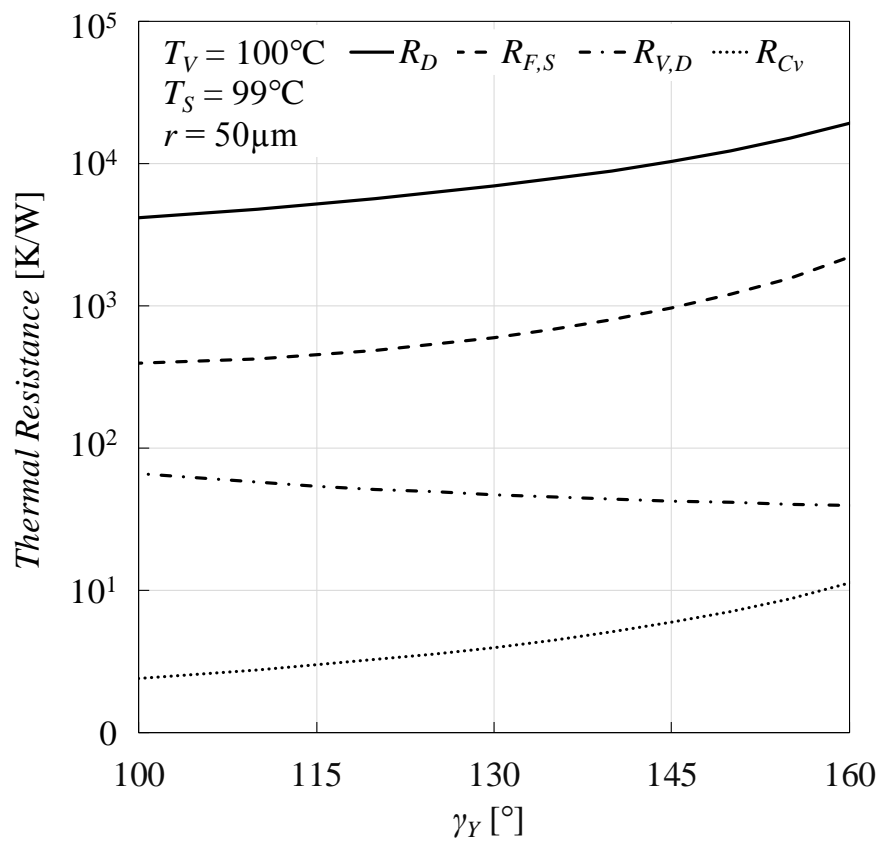

Figure 10. Thermal resistances $R_{D}, R_{F, S}, R_{V, D}$, and $R_{C v}$ for varying $\gamma_{Y}$ at constant droplet radius $r=50 \mu \mathrm{m}, T_{V}-$

$$
T_{S}=1 \mathrm{~K}
$$


When comparing the heat transfer coefficient with the one obtained through Equation 4 according to Nusselt theory for similar temperature difference and thermal properties, DWC can generally lead to larger heat transfer coefficients, hence dropwise condensation is a preferred phase-change mode. Consequently, the goal here is to achieve very large heat transfer coefficients by using surfaces with pre-defined hexagonal structures having superhydrophobic property. For a contact angle of $150^{\circ}$, heat transfer coefficients of approximately $19.5 \mathrm{~kW} / \mathrm{m}^{2} \mathrm{~K}, 25 \mathrm{~kW} / \mathrm{m}^{2} \mathrm{~K}$, and $37.5 \mathrm{~kW} / \mathrm{m}^{2} \mathrm{~K}$ can be obtained for droplets of the radius of $100 \mu \mathrm{m}, 75 \mu \mathrm{m}$, and $50 \mu \mathrm{m}$, respectively. However, to achieve such large heat transfer performance, one has to ensure enough spacing between the droplets (i.e. nucleation cavities) before accumulation occurs with each other. As the contact angle increases, the predictions show that the heat transfer coefficient will remarkably rise towards 10 times magnitude compared to the case with FWC. Hence the main target here was to get contact angles larger than $150^{\circ}$.

For the interpretation of the heat transfer performance, the thermal resistances determined by the vapor-droplet interface $R_{V, D}$, curvature $R_{C V}$, liquid droplet $R_{D}$, and the region droplet foot-substrate $R_{F, S}$ (see Figure 7) are exemplary presented in Figure 10 for $r=50 \mu \mathrm{m}$ with respect to contact angle and $T_{V}-T_{S}=1 \mathrm{~K}$. All thermal resistances increase with contact angle except $R_{V, D}$, which might be due to the reason that the skin surface of the spherical caplike droplet increases and provides larger area for the condensation of vapor molecules. With larger contact angle, $R_{V, D}$ converges to a minimum value, while the difference from of $\gamma_{Y}=100^{\circ}$ and $\gamma_{Y}=160^{\circ}$ is not large compared to the sum of the rest of the thermal resistances. Roughly it can be concluded that the overall resistance increase by 100 times when contact angle is enlarged from $100^{\circ}$ to $160^{\circ}$.

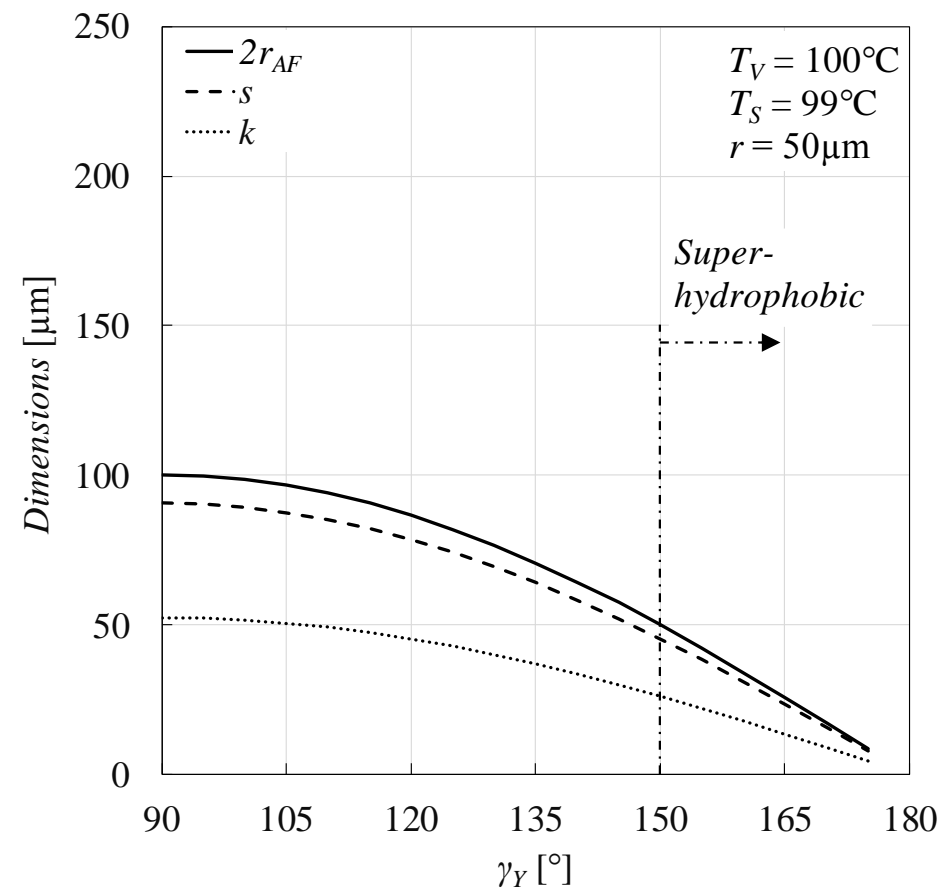

Figure 11. Variation of edge length $k$, width $s$ of a single hexagon and foot diameter $2 r_{A F}$ of droplet for a droplet for different contact angles $\gamma_{Y}$ for droplet radius $r=50 \mu \mathrm{m}, T_{V}=100^{\circ} \mathrm{C}$, and $T_{S}=99^{\circ} \mathrm{C}$

For the first evaluation, this looks like a drawback for the heat flow rate. But when reading the calculations for the droplet foot diameter $\left(2 r_{A F}\right)$, the heat transfer coefficient increases, since the area where the heat flow is transported decreases significantly (see Figure 11). This can be supposed as one of the major reasons for the rise in heat transfer coefficient at increased contact angles. In Figure 11, the variation of the edge length $k$, width $s$ of a single hexagon micro-structure as well as the diameter of droplet foot $2 r_{A F}$ is illustrated as a function of contact angle for a given droplet radius of $50 \mu \mathrm{m}$ and $T_{V}-T_{S}=1 \mathrm{~K}$. As the contact angle gets larger, all three parameters decrease, while 
the values merge at zero for $180^{\circ}$, since according to Equation 13 the resulting foot area is also zero due to $\sin ^{2}\left(180^{\circ}\right)=0$.

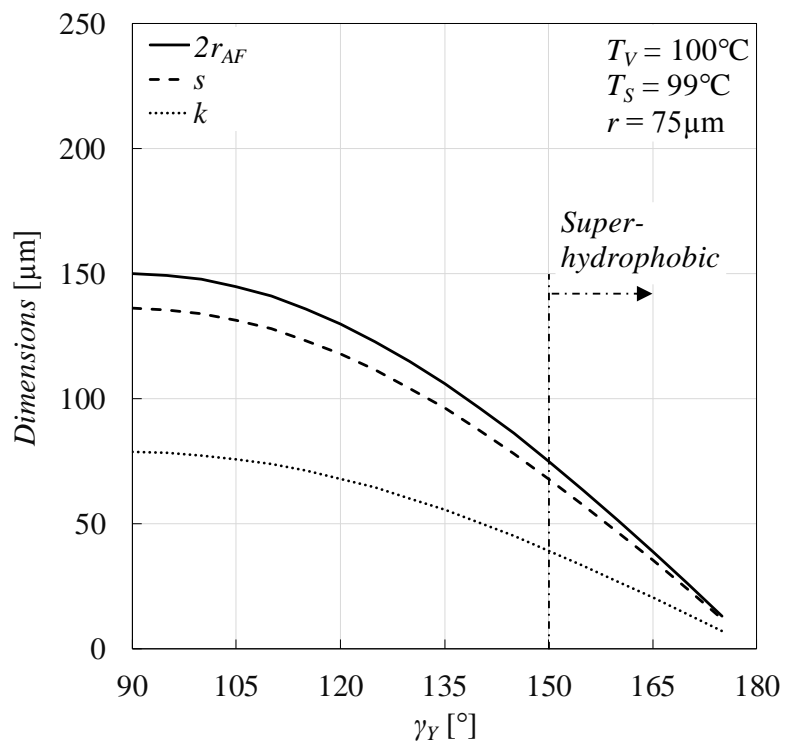

Figure 12. Variation of edge length $k$, width $s$ of a single hexagon and foot diameter $2 r_{A F}$ of droplet for a droplet for different contact angles $\gamma_{Y}$ for droplet radius $r=75 \mu \mathrm{m}, T_{V}=100^{\circ} \mathrm{C}$, and $T_{S}=99^{\circ} \mathrm{C}$

Similar behavior can be seen for the cases with $r=75 \mu \mathrm{m}$ and $r=100 \mu \mathrm{m}$ as shown in Figure 12 and Figure 13. As explained before, to guarantee an enhanced thermal performance with DWC, the surface has to exhibit a superhydrophobic behavior $\left(\gamma_{Y}>150^{\circ}\right)$. Therefore, the calculations concerning the geometric dimensions such as edge length and width of the hexagonal micro-spot predict that their values should be $k<26 \mu \mathrm{m}, s<43 \mu \mathrm{m}$ for $r=50 \mu \mathrm{m}$, $k<39 \mu \mathrm{m}, s<68 \mu \mathrm{m}$ for $r=75 \mu \mathrm{m}$, and $k<52 \mu \mathrm{m}, s<90 \mu \mathrm{m}$ for $r=100 \mu \mathrm{m}$.

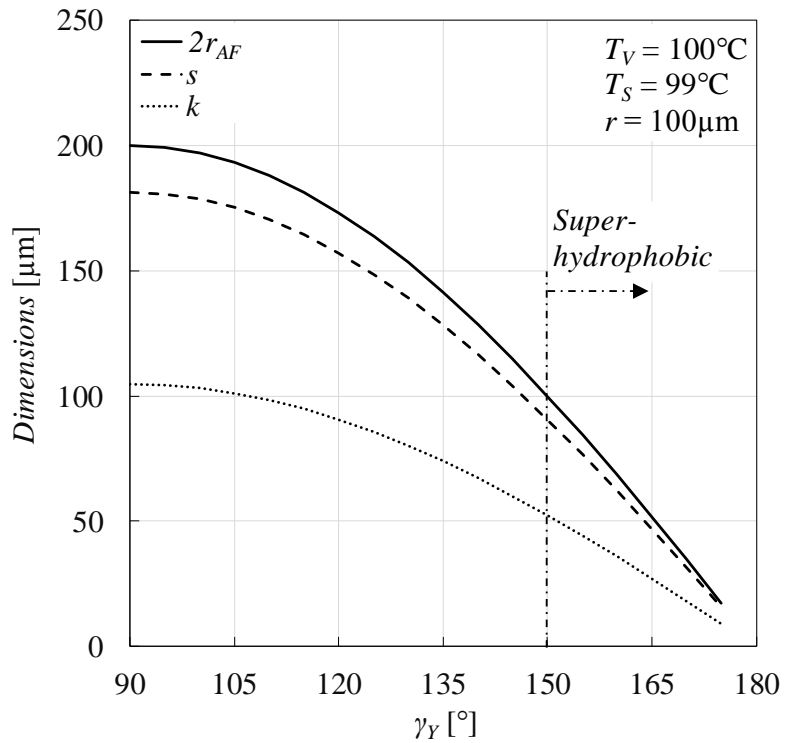

Figure 13. Variation of edge length $k$, width $s$ of a single hexagon and foot diameter $2 r_{A F}$ of droplet for a droplet for different contact angles $\gamma_{Y}$ for droplet radius $r=100 \mu \mathrm{m}, T_{V}=100^{\circ} \mathrm{C}$, and $T_{S}=99^{\circ} \mathrm{C}$ 
As a reverse conclusion, this means the smaller the above-mentioned parameters become, the larger the contact angle and thus leading to a heat transfer enhancement with micron-sized droplets. However, this was not achievable due to technical limitations of the manufacturing as well as due to spot size of the laser beam. Furthermore, the laser positioning accuracy also was not sufficient for the manufacturing of smaller hexagons, e.g. $k<15 \mu \mathrm{m}$, and $s<20 \mu \mathrm{m}$, respectively. Another geometric parameter which can influence the thermal resistance $R_{F, S}$ (see Figure 7) and hence the heat transfer performance are the thickness and the depth of the nano-structure and micro-structure, respectively. Assuming a constant and homogenous contact angle of $150^{\circ}$, a droplet radius of $50 \mu \mathrm{m}$ and a subcooling of $1 \mathrm{~K}, R_{F, S}$ rises when the depth $z_{m}$ of the micro-structure increases for constant layer thickness $z_{n}$ of the nano-structure (see Figure 14). This can be attributed to the fact that more liquid $(0.677 \mathrm{~W} / \mathrm{mK})$ with lower thermal conductivity than the substrate material $(196 \mathrm{~W} / \mathrm{mK})$ will exist in the hexagon indentation, leading to an enlargement of thermal resistance.

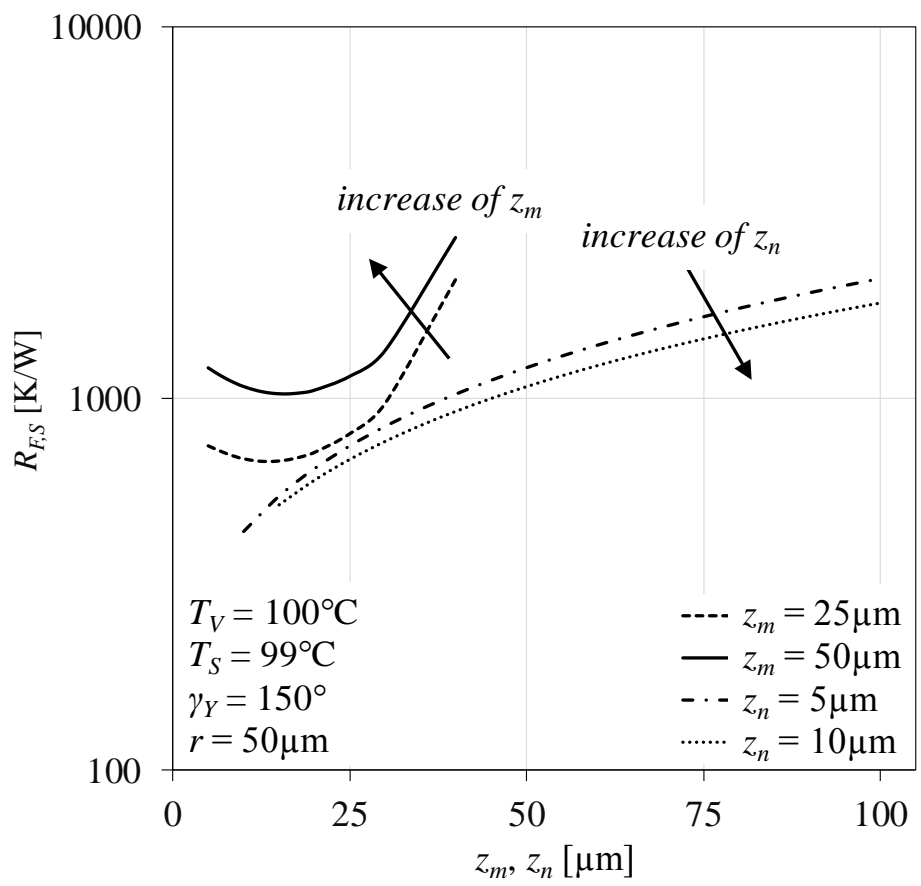

Figure 14. Variation of thermal resistance $R_{F, S}$ existing between droplet foot and surface for different depths of micro-structure $z_{m}$ and thickness of nano-structure $z_{n}$ at constant droplet radius $r=50 \mu \mathrm{m}, T_{V}=100^{\circ} \mathrm{C}, T_{S}=99^{\circ} \mathrm{C}$, and contact angle $\gamma_{Y}=150^{\circ}$

Vice versa, $R_{F, S}$ can be reduced when the layer thickness $z_{n}$ of the nano-structure obtained through electrochemical etching $\left(\mathrm{Al}_{2} \mathrm{O}_{3}\right)$ increases. However, the potential for reduction of $R_{F, S}$ for the latter case is only remarkable for large $z_{m}$ due to the shape of the hexagon geometry. This trend has to be cross-checked with the predictions for $k$ and $s$, where maximum values are forecasted in order to keep the contact angle above $150^{\circ}$ (see Figure 11-Figure 13). At constant $z_{m}$, the thermal resistance $R_{F, S}$ between the droplet foot and the substrate base first reduces with increasing nano-structure layer thickness up to $z_{n} \approx 15 \mu \mathrm{m}$. This can be ascribed to the reduction of liquid mass inside the hexagon indentation leading to a better thermal conduction from the droplet foot towards the substrate base. To note, at the same time the layer thickens at the solid-liquid interface. For $z_{n}>15 \mu \mathrm{m}$, a notably increase of $R_{F, S}$ is predicted, while at comparable values between both the geometric parameters, the rate in contribution $R_{F, S}$ is larger for $z_{n}$ than $z_{m}$. Since the nano-structure fills now the hexagon indentation as well as exists as a thicker layer at the solid-liquid interface compared to the micro-structure as high conductive material, the low conductive aluminum oxide layer is dominant and leads to larger obstacle in terms of heat transport. The dominance of $z_{n}$ on $R_{F, S}$ significantly increases when larger $z_{m}$ values are manufactured. This analysis suggested that the values for the thickness $z_{n}$ and depth $z_{m}$ of the nano- and 
micro-structure should be roughly limited to $25 \mu \mathrm{m}$ each in order to keep the thermal resistance $R_{F, S}$ as low as possible, provided this can be ensured by the laser-manufacturing technology used in this study.

\section{Manufacturing of Nano-Micro-Structured 7075 Aluminum Substrates}

According to the predictions and calculations made as described in the previous section, several aluminum substrates have been treated with laser-ablation in order to achieve the preliminary determined geometric dimensions. All in all, 15 substrates with variation of edge length $k$, width $s$, depth $z_{m}$, thickness of edge $G$, and the hexagon density per unit area $x, y$ have been fabricated. As predicted in Figure 11-Figure 13, the geometric dimensions $k$ and $s$ could be realized by using laser-ablation technique within the spectrum of $25 \mu \mathrm{m}-50 \mu \mathrm{m}$ and $43 \mu \mathrm{m}-90 \mu \mathrm{m}$, respectively, by keeping the depth of the hexagons and the edge thickness constant at $z_{m}=40 \mu \mathrm{m}$ and $G=75 \mu \mathrm{m}$ (see Figure 15 ). The depth $z_{m}$ has been measured through a high-precision micrometer stage attached to the microscope. First the lens of the microscope was sharply focused on the trough of the cavity and this position was set to $z_{m}=0$. In a second step the lens was targeted onto the crest (hexagon edge) and the reading was done for the depth $z_{m}$. Overall, the measurement accuracy for all parameters was smaller than $\pm 1 \mu \mathrm{m}$.

a)

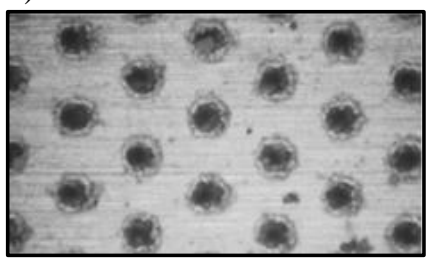

d)

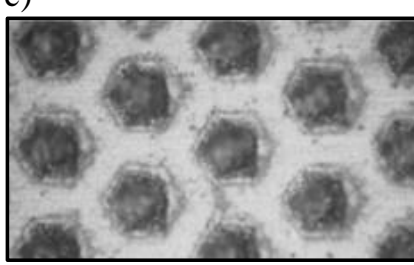

b)

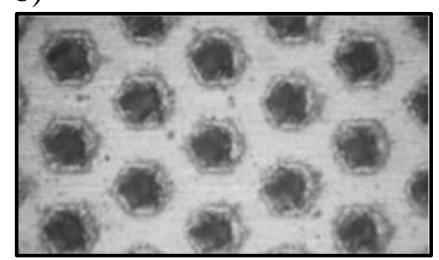

e)

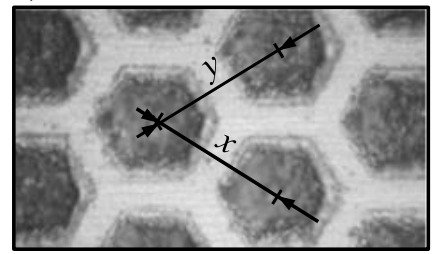

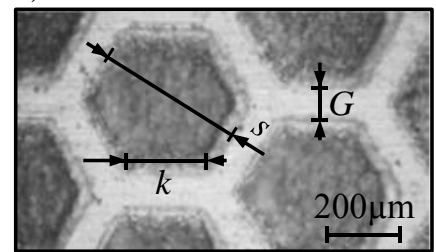

\begin{tabular}{c|c|c|c|c|c}
\hline Sample No. & $k[\mu \mathrm{m}]$ & $s[\mu \mathrm{m}]$ & $z_{m}[\mu \mathrm{m}]$ & $G[\mu \mathrm{m}]$ & $x, y[\mu \mathrm{m}]$ \\
\hline a) & 25 & 43 & & & 81 \\
b) & 50 & 87 & & & 124 \\
c) & 75 & 130 & 40 & 75 & 167 \\
d) & 125 & 217 & & & 254 \\
e) & 175 & 303 & & & 341
\end{tabular}

Figure 15. Micro-structured surfaces manufactured for various edge length $k$ with resulting width $s$ and density per unit area of hexagonal structure $x, y$ at constant depths $z_{m}$ and edge thickness $G$. The resolution of the images is indicated with a scale bar in image e)

In order to compare and verify the broader effect of $k$ and $s$ on contact angle and hence later on the overall heat transfer based on the model calculations, larger values for the edge length and width have been manufactured. The variation of density per unit area of hexagonal structure $x, y$ changed due to the increase of $k$ (hence $s$ ), since the portion of hexagon area which occupies the unit area enlarged. When looking at the images Figure 15a) - Figure 15e), it can be identified that as larger $k$ was adjusted during the manufacturing, the symmetry of the hexagon could be controlled much more precisely and sharper corners resulted. The shape of the micro-structures became more circlelike when the size of the hexagon decreased. This might be due to the laser used in this study which had a focus diameter of $15 \pm 2 \mu \mathrm{m}$ with a F-Theta lens and a maximum laser bean energy of $1 \mathrm{~mJ}$. 
f)

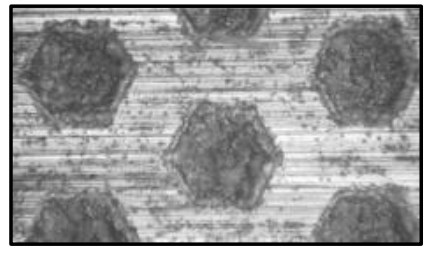

g)

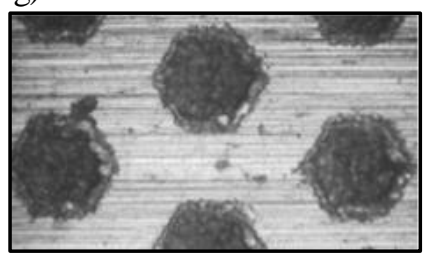

h)

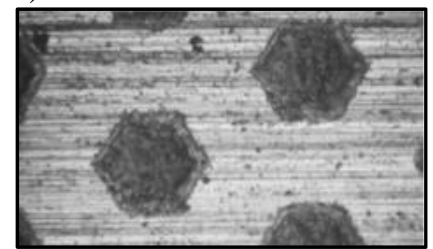

\begin{tabular}{c|c|c|c|c|c}
\hline Sample No. & $k[\mu \mathrm{m}]$ & $s[\mu \mathrm{m}]$ & $z_{m}[\mu \mathrm{m}]$ & $G[\mu \mathrm{m}]$ & $x, y[\mu \mathrm{m}]$ \\
\hline $\mathrm{f})$ & & & 6 & & \\
$\mathrm{~g})$ & 100 & 173 & 20 & 125 & 211 \\
$\mathrm{~h})$ & & & 40 & &
\end{tabular}

Figure 16. Micro-structured surfaces manufactured for various depth $z_{m}$ of hexagonal structure at constant edge length $k$, width $s$, edge thickness $G$, and density per unit area of hexagonal structure $x, y$, respectively. The resolution of the images is similar to those of images shown in Figure 15

To investigate the effect of hexagon depth $z_{m}$, three values could be adjusted during surface fabrication as illustrated in Figure 16. The parameters $k$ (hence $s), G$ and $x, y$ have been kept constant at $100 \mu \mathrm{m}(173 \mu \mathrm{m}), 75 \mu \mathrm{m}$, and $211 \mu \mathrm{m}$, respectively. The microscopic images f) - h) in Figure 16 do not reveal any significant geometric differences when $z_{m}$ was decreased, however, slight variation of edge quality can be observed for a few hexagons.
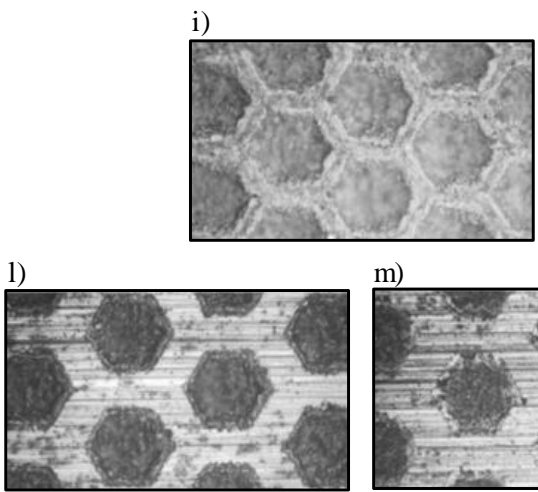
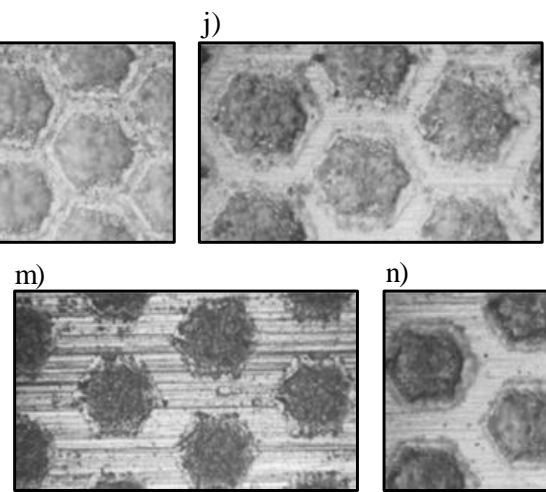

k)
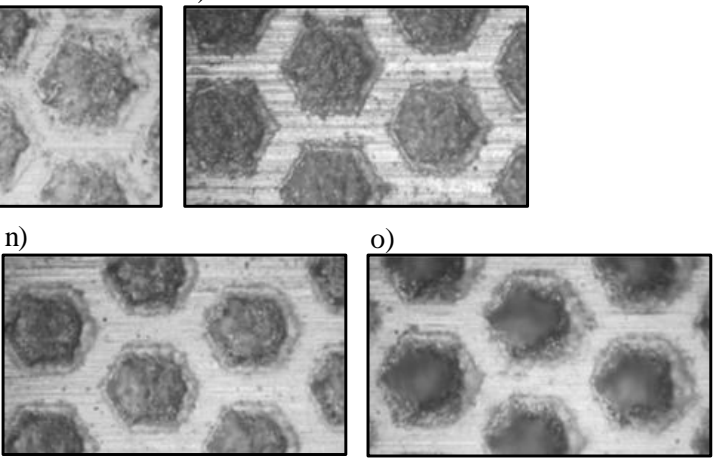

\begin{tabular}{c|c|c|c|c|c}
\hline Sample No. & $k[\mu \mathrm{m}]$ & $s[\mu \mathrm{m}]$ & $z_{m}[\mu \mathrm{m}]$ & $G[\mu \mathrm{m}]$ & $x, y[\mu \mathrm{m}]$ \\
\hline i) & & & & 25 & 186 \\
j) & & & & 50 & 198 \\
k) & & & & 75 & 211 \\
1) & \multirow{2}{*}{100} & \multirow{2}{*}{173} & 20 & 100 & 223 \\
$\mathrm{~m})$ & & & & 125 & 236 \\
$\mathrm{n})$ & & & & 150 & 248 \\
o) & & & & 175 & 261
\end{tabular}

Figure 17. Micro-structured surfaces manufactured for various density of hexagonal structure per unit area $x, y$ at constant edge length $k$, width $s$, and depth $z_{m}$. The resolution of the images is similar to those of images shown in

Figure 15

The last variation was done with the edge thickness parameter $G$ ranging from $25 \mu \mathrm{m}$ to $175 \mu \mathrm{m}$ at constant $k=100 \mu \mathrm{m}$ (respectively $s=173 \mu \mathrm{m}$ ) and $z_{m}=20 \mu \mathrm{m}$ as shown in Figure 17. The minimum and maximum distances determining the hexagon density per unit area resulted to $186 \mu \mathrm{m}$ and $261 \mu \mathrm{m}$. When investigating the images i) to o), one can clearly identify the increase in edge thickness, while a rather constant shape and symmetry of the hexagon 
micro-structures could be guaranteed. Except for surface presented in images $\mathrm{m}$ ) to o), the edges could not be sharply manufactured. This maybe can be attributed to the surface quality before laser ablation, since reflections of the laser beam might have influenced the focusing as well as the concentration of the laser energy as a local hot spot.

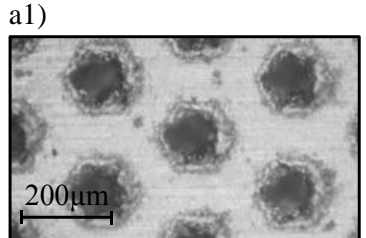

a2)

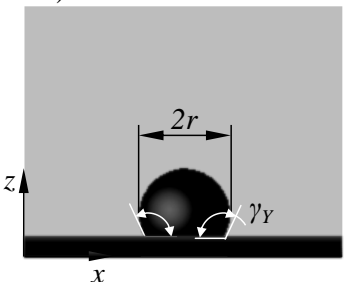

b1)

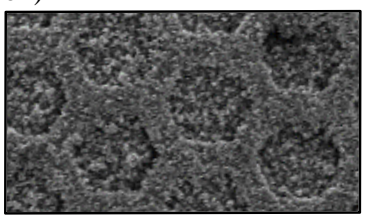

b2)

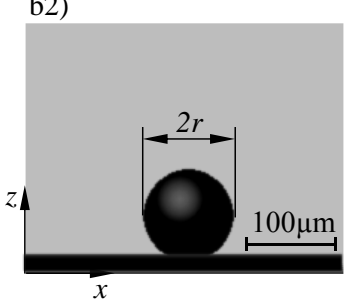

Figure 18. Exemplary result of micro-structured surface ( $k=50 \mu \mathrm{m}, s=87 \mu \mathrm{m}, z_{m}=40 \mu \mathrm{m}, G=75 \mu \mathrm{m}$, $x, y=223 \mu \mathrm{m}$ ) when treating with electrochemical etching: a1) surface topography before electrochemical etching, a2) contact angle before electrochemical etching, b1) surface topography after electrochemical etching, b2) contact angle after electrochemical etching. The resolution of the images is given with a scale bar

After manufacturing with laser ablation, contact angle measurements have been carried out by using sessile droplet method and a tensiometer (KSV ATTENSION, Theta Lite, Optic Contact Angle Tensiometer) using deionized water. Several micro-droplets with a constant diameter of $0.1 \mathrm{~mm}$ were placed on the surfaces, while care has been taken to pin the droplet at one single cavity and sitting recognizable within the field of view of the camera of the Tensiometer device (see Figure 18a2). The measurement accuracy of contact angle is given by the device manufacturer as $\pm 2^{\circ}$. The resulting contact angles for all surfaces were ranging within the spectrum $100^{\circ}-120^{\circ}$ before electrochemical etching was conducted. The latter treatment has been step-by-step realized by using ethanol bath where the samples were drained into and stimulated by an ultrasound in order to remove depositions over at least $5 \mathrm{~min}$. Subsequently, the samples were wetted at minimum $50^{\circ} \mathrm{C}$ in $1 \mathrm{~mol} / \mathrm{L}$ sodium hydroxide for 180 seconds to get rid of the oxide boundary. Using a solution of $2.4 \mathrm{~mol} / \mathrm{L}$ nitric acid, all samples were dipped one-by-one over $3 \mathrm{~min}$. to achieve neutralization of the surfaces.

Table 1. Static contact angles $\gamma_{\mathrm{Y}}$ measured on surface after electrochemical etching of laser ablated micro-structures

\begin{tabular}{|l|c|c|c|c|c|c|c|c|c|c|c|c|c|c|c|}
\hline $\begin{array}{l}\text { Sample } \\
\text { No. }\end{array}$ & a) & b) & c) & d) & e) & f) & g) & h) & i) & j) & k) & l) & m) & n) & o) \\
\hline $\begin{array}{l}\text { Contact } \\
\text { angle } \gamma_{Y}\end{array}$ & $162^{\circ}$ & $158^{\circ}$ & $155^{\circ}$ & $152^{\circ}$ & $153^{\circ}$ & $154^{\circ}$ & $155^{\circ}$ & $154^{\circ}$ & $158^{\circ}$ & $157^{\circ}$ & $157^{\circ}$ & $155^{\circ}$ & $154^{\circ}$ & $154^{\circ}$ & $154^{\circ}$ \\
\hline
\end{tabular}

The results for heat transfer coefficient calculation for the subcooling temperature $\boldsymbol{T}_{\boldsymbol{V}}-\boldsymbol{T}_{\boldsymbol{S}}$ ranging up to $20 \mathrm{~K}$ is illustrated in Figure 5. All thermopyhsical properties are considered based on the bulk mean temperature 0.5 $\left(\boldsymbol{T}_{V}+\boldsymbol{T}_{S}\right)$. At the saturation condition $100^{\circ} \mathrm{C}$, the heat transfer coefficient decreases with increasing subcooling temperature, since the thickness of condensed liquid film leads to a larger thermal resistance. When higher saturation temperature for vapor is assumed, a minor increase in heat transfer performance is predicted by the Nusselt theory for comparable subcooling temperature. This is mostly attributed to the larger driving temperature difference between the surface of the wall and the vapor [30]. Subsequent to electrochemical treatment of all surfaces (see example in Figure $18 \mathrm{~b} 1$ ), the contact angle increased as shown exemplarily in Figure $18 \mathrm{~b} 2$ at all surfaces. The corresponding contact 
angles for each surface is displayed in Table 1. The reason for larger $\gamma_{Y}$ might be due to the aluminum oxide layer existing as nano-structures on the surface which decreased the surface energy between solid and liquid, hence leading to a much more spherical shape of the droplet. Although for most of the samples, superhydrophobicity was achieved, deviations resulted for increasing $k$ (see values of samples a) - d)) and $G$ (see values of samples i) - m)), while the variation in $z_{m}$ did not lead to a significant difference in contact angle. The previously mentioned goal to obtain increased contact angles on rather comparable $k$ and $z_{m}$ values as predicted by the heat transfer calculations has been reasonably - achieved in this case. However, the substrates have to be investigated further concerning their performance in heat transfer, wettability and long-term durability in condensation experiments as mentioned before to proof and validate the overall approach of conceptualization and realization presented in this work. Therefore, the focus on dropwise condensation on nano-micro-structured surfaces which have been developed in this study will still remain as a future experimental work which will be reported in a separate paper.

\section{CONCLUSION AND OUTLOOK}

In the present study, systematic conceptualization of nano-micro-structured surfaces to obtain dropwise condensation has been carried out by utilizing heat transfer modelling. For this purpose, thermal resistances method at one single condensing droplet has been used for varying droplet radius, resulting contact angle and geometric dimensions of micro-structure geometry. For the latter, a hexagonal shape has been chosen in order to use the entire surface efficiently. The reason for the choice of this geometry was used due to the fact that in previous studies done by others it has been found that surface embossed with this geometry can exhibit superhydrophobic wetting behavior. Another reason for the selection of the hexagonal shape was to achieve the largest possible usage area at the smallest distance setting. Threshold values such as depth and edge length of the micro-structure, and nano-layer thickness have been analyzed and minimum and maximum values have been analyzed by considering a solid-liquid contact angle of $150^{\circ}$ minimum at which superhydrophobicity starts. The predictive calculations done in this study show that to obtain heat transfer coefficients twice as large of those calculated through the Nusselt theory for filmwise condensation is possible when the edge length and the depth of the micro-structures do not exceed $50 \mu \mathrm{m}$ and $25 \mu \mathrm{m}$ at contact angles of $150^{\circ}$ and a subcooling of $1 \mathrm{~K}$ for a maximum droplet radius of $100 \mu \mathrm{m}$. While the thickness of the nano-structuring should be kept at $12 \mu \mathrm{m}-15 \mu \mathrm{m}$, the spacing parameter (defines the density of hexagons per unit area) can be adjusted to a maximum value of approximately $200 \mu \mathrm{m}$. Based on the calculations, laser ablation technique and electrochemical etching have been adopted to 7075 aluminum samples for the manufacturing of micro-structures and nano-structures, respectively. microscopic images reveal that as the size of the edge length $k$ of hexagons increase, the symmetry, edges and corners of the geometry becomes distinctively sharper, independently of density and depth of the micro-structure. Contact angle measurements show that supherhydrophobic surface property could be achieved on all surfaces, however the contact angle on some samples were close to the threshold of $150^{\circ}$.

In summary, by using mathematical modelling approach, a nano-micro-structure geometry has been pre-designed to achieve defined surface characteristic depending on relevant operating parameters at dropwise condensation mode. Most of the designed structure dimensions have been successfully manufactured by means of laser machining and electrochemical etching. The resulting contact angles of droplets placed on the fabricated surfaces are satisfyingly within the superhydrophobic contact angle range necessary for the achievement of high heat transfer performance as forecasted with predictive calculation. Further investigations will be carried out in a separate study by performing condensation experiments in order to validate the heat transfer performance and analyze the long-term stability of the nano-micro-structured surfaces.

\section{ACKNOWLEDGEMENT}

The author thanks the Deutsche Forschungsgemeinschaft (DFG, German Research Foundation) - Funding Nr. 441193154 and the EVATEG Center of the Özyeğin University for their support. Furthermore, the author thanks to M.Sc. Arda Cetiner from the Mechanical Engineering Department of the Turkish-German University, for his support during microscopic measurements of the micro-structured substrates.

\section{NOMENCLATURE}




\begin{tabular}{|c|c|}
\hline$A_{B r\left(\sqrt{3} k-2 z_{n}\right)}$ & $\begin{array}{l}\text { Heat transfer area at the liquid bridge in } z \text {-direc- } \\
\text { tion, }\left[\mathrm{m}^{2}\right]\end{array}$ \\
\hline$A_{F}$ & $\begin{array}{l}\text { Heat transfer area formed by contact between } \\
\text { droplet foot, three-phase contact line and hexag- } \\
\text { onal structure without the region of liquid } \\
\text { bridge and that of the nano-structure layer } \\
\left(z_{n}+z_{m}\right),\left[\mathrm{m}^{2}\right]\end{array}$ \\
\hline$A_{H \operatorname{exa}(\sqrt{3} \mathrm{k})}$ & $\begin{array}{l}\text { Projected heat transfer area of hexagonal struc- } \\
\text { ture, }\left[\mathrm{m}^{2}\right]\end{array}$ \\
\hline$A_{m}, A_{n}$ & $\begin{array}{l}\text { Projected heat transfer area based on nano-, Mi- } \\
\text { cro-structure, }\left[\mathrm{m}^{2}\right]\end{array}$ \\
\hline$A_{n\left(z_{m}+z_{n}\right)}$ & $\begin{array}{l}\text { Projected heat transfer area of based on depth of } \\
\text { micro-structure and thickness of nano-structure, } \\
{\left[\mathrm{m}^{2}\right]}\end{array}$ \\
\hline$A_{P}$ & Condensation area on plate (substrate), $\left[\mathrm{m}^{2}\right]$ \\
\hline$e_{s g}, e_{s l}, e_{l g}$ & $\begin{array}{l}\text { Surface energy at the interfaces solid-gas, solid- } \\
\text { liquid, liquid-gas, }[\mathrm{Nm}]\end{array}$ \\
\hline$G$ & Edge thickness, $[\mu \mathrm{m}]$ \\
\hline$g$ & Gravitational acceleration, $\left[\mathrm{ms}^{-2}\right]$ \\
\hline$h_{e v}$ & $\begin{array}{l}\text { Latent heat of evaporation (ref. REFPROP), } \\
{\left[\mathrm{Jkg}^{-1}\right]}\end{array}$ \\
\hline$k$ & Edge length of hexagon, $[\mu \mathrm{m}]$ \\
\hline $\mathrm{M}_{\mathrm{H}_{2} \mathrm{O}}$ & Liquid mass flow rate, $\left[\mathrm{kgs}^{-1}\right]$ \\
\hline$p_{V}$ & Vapor pressure, $\left[\mathrm{Nm}^{-2}\right]$ \\
\hline$Q_{P}, Q$ & $\begin{array}{l}\text { Heat flow rate through a plate, through a single } \\
\text { droplet, [W] }\end{array}$ \\
\hline REFPROP & $\begin{array}{l}\text { National Institute of Standards and Technology } \\
\text { Reference Fluid Thermodynamic and Transport } \\
\text { Properties Database }\end{array}$ \\
\hline$R_{B r}$ & $\begin{array}{l}\text { Thermal resistance of liquid bridge existing in } \\
\text { hexagonal structure, }\left[\mathrm{kW}^{-1}\right]\end{array}$ \\
\hline$R_{C v}$ & $\begin{array}{l}\text { Thermal resistance due to curvature of droplet, } \\
{\left[\mathrm{kW}^{-1}\right]}\end{array}$ \\
\hline$R_{D}$ & $\begin{array}{l}\text { Thermal resistance within droplet, time-depend- } \\
\text { ent thermal resistance within droplet }\left[\mathrm{kW}^{-1}\right]\end{array}$ \\
\hline$R_{F, S}$ & $\begin{array}{l}\text { Thermal resistance between droplet foot and } \\
\text { substrate surface, }\left[\mathrm{kW}^{-1}\right]\end{array}$ \\
\hline$R_{m}, R_{n}$ & $\begin{array}{l}\text { Thermal resistance of micro-structure }(\mathrm{Al} / \mathrm{Cu}) \text {, } \\
\text { nano-structure }(\mathrm{Al} 203 / \mathrm{CuO}),\left[\mathrm{kW}^{-1}\right]\end{array}$ \\
\hline$R_{V}$ & $\begin{array}{l}\text { Gas constant (ref. REFPROP) of vapor, } \\
{\left[\mathrm{Jkg}^{-1} \mathrm{~K}^{-1}\right]}\end{array}$ \\
\hline$R_{V, D}$ & $\begin{array}{l}\text { Thermal resistance at the vapor-droplet-inter- } \\
\text { face, }\left[\mathrm{kW}^{-1}\right]\end{array}$ \\
\hline$R_{z_{n}+z_{m}}$ & $\begin{array}{l}\text { Thermal resistance of nano-structure along the } \\
\text { height } z_{n}+z_{m},\left[\mathrm{~kW}^{-1}\right]\end{array}$ \\
\hline$r$ & Droplet radius, $[\mathrm{m}, \mathrm{mm}, \mu \mathrm{m}]$ \\
\hline$S$ & Width of hexagon, $[\mu \mathrm{m}]$ \\
\hline
\end{tabular}




\begin{tabular}{|c|c|}
\hline$S_{n}$ & Thickness of nano-structure layer, $[\mu \mathrm{m}]$ \\
\hline$T_{D}$ & Temperature at droplet-vapor interface, $[\mathrm{K}]$ \\
\hline$T_{F}$ & Temperature at droplet foot, $[\mathrm{K}]$ \\
\hline$T_{\mathrm{H}_{2} \mathrm{O}, \mathrm{in}}$ & Cooling liquid inlet temperature, $[\mathrm{K}]$ \\
\hline$T_{\mathrm{H}_{2} \mathrm{O}, \mathrm{out}}$ & Cooling liquid outlet temperature, $[\mathrm{K}]$ \\
\hline$T_{S}$ & Surface temperature of substrate, $[\mathrm{K}]$ \\
\hline$T_{V}$ & Vapor temperature, $[\mathrm{K}]$ \\
\hline$T_{W}$ & Temperature measured in substrate wall, $[\mathrm{K}]$ \\
\hline$\Delta T_{C v}$ & $\begin{array}{l}\text { Temperature difference due to curvature of } \\
\text { droplet, }[\mathrm{K}]\end{array}$ \\
\hline$\Delta T_{D, F}$ & $\begin{array}{l}\text { Temperature difference at the foot of droplet at } \\
\text { the so-called three-phase contact line, }[\mathrm{K}]\end{array}$ \\
\hline$\Delta T_{F, S}$ & $\begin{array}{l}\text { Temperature difference between droplet foot } \\
\text { and substrate surface, }[\mathrm{K}]\end{array}$ \\
\hline$\Delta T_{V, D}$ & $\begin{array}{l}\text { Temperature difference at the vapor-droplet-in- } \\
\text { terface, }[\mathrm{K}]\end{array}$ \\
\hline$\Delta T_{V, S}$ & $\begin{array}{l}\text { Temperature difference between vapor and sur- } \\
\text { face of substrate, }[\mathrm{K}]\end{array}$ \\
\hline$v_{V}$ & $\begin{array}{l}\text { Specific volume (ref. REFPROP) of vapor, } \\
{\left[\mathrm{m}^{3} \mathrm{~kg}^{-1}\right]}\end{array}$ \\
\hline$x, y, z$ & Coordinate axis, coordinate, $[\mathrm{m}]$ \\
\hline$z_{m}$ & Depth of hexagonal structure, $[\mu \mathrm{m}]$ \\
\hline$z_{n}$ & Thickness of nano-structure, $[\mu \mathrm{m}]$ \\
\hline$\Delta z$ & Distance in $z$-direction, $[\mathrm{m}, \mu \mathrm{m}]$ \\
\hline $\begin{array}{l}\alpha, \alpha_{V, D} \\
\alpha_{\max }\end{array}$ & $\begin{array}{l}\text { Heat transfer coefficient (HTC), HTC at the va- } \\
\text { por-droplet interface, maximum } \mathrm{HTC},\left[\mathrm{kWm}^{-}\right. \\
\left.{ }^{2} \mathrm{~K}^{-1}\right]\end{array}$ \\
\hline$\gamma_{Y}$ & Young contact angle, $\left[^{\circ}\right]$ \\
\hline$\varepsilon$ & Condensation coefficient, [-] \\
\hline$\lambda_{D}$ & $\begin{array}{l}\text { Thermal conductivity of droplet (ref. } \\
\text { REFPROP), }\left[\mathrm{Wm}^{-1} \mathrm{~K}^{-1}\right]\end{array}$ \\
\hline$\lambda_{L}$ & $\begin{array}{l}\text { Thermal conductivity of liquid (ref. } \\
\text { REFPROP), }\left[\mathrm{Wm}^{-1} \mathrm{~K}^{-1}\right]\end{array}$ \\
\hline$\lambda_{m}$ & $\begin{array}{l}\text { Thermal conductivity of micro-structure (ref. } \\
\text { VDI-Heat Atlas), }\left[\mathrm{Wm}^{-1} \mathrm{~K}^{-1}\right]\end{array}$ \\
\hline$\lambda_{n}$ & $\begin{array}{l}\text { Thermal conductivity of nano-structure, (ref. } \\
\text { VDI-Heat Atlas), }\left[\mathrm{Wm}^{-1} \mathrm{~K}^{-1}\right]\end{array}$ \\
\hline$\lambda_{P}$ & $\begin{array}{l}\text { Thermal conductivity of plate, } \\
{\left[\mathrm{Wm}^{-1} \mathrm{~K}^{-1}\right]}\end{array}$ \\
\hline$\mu_{L}$ & Dynamic viscosity of liquid, $\left[\mathrm{kgm}^{-1} \mathrm{~s}^{-1}\right]$ \\
\hline$\rho_{D}, \rho_{V}, \rho_{L}$ & $\begin{array}{l}\text { Density of droplet, vapor and liquid (ref. } \\
\text { REFPROP), }\left[\mathrm{kgm}^{-3}\right]\end{array}$ \\
\hline$\sigma_{D}$ & Droplet surface tension (ref. REFPROP), $\left[\mathrm{Nm}^{-1}\right]$ \\
\hline
\end{tabular}




\section{REFERENCES}

[1] Giradkar PD, Wankhede US. High Heat Flux Micro-Electronics Cooling. International Journal of Modern Engineering Research 2013;3:336-41.

[2] Launay S, Sartre V, Bonjour J. Parametric analysis of loop heat pipe operation: a literature review. International Journal of Thermal Sciences 2007;46:621-36. https://doi.org/10.1016/j.ijthermalsci.2006.11.007.

[3] Ma X, Chen J, Li S, Sha Q, Liang A, Li W, et al. Application of absorption heat transformer to recover waste heat from a synthetic rubber plant. Applied Thermal Engineering 2003;23:797-806. https://doi.org/https://doi.org/10.1016/S1359-4311(03)00011-5.

[4] Jo H, Yu DI, Noh H, Park HS, Kim MH. Boiling on spatially controlled heterogeneous surfaces: Wettability patterns on microstructures. Applied Physics Letters 2015;106:181602. https://doi.org/10.1063/1.4919916.

[5] Zhong Y, Jacobi AM, Georgiadis JG. Condensation and Wetting Behavior on Surfaces With Micro-Structures : Super-Hydrophobic and Super-Hydrophilic. International Refrigeration and Air Conditioning Conference at Purdue University 2006:R100, 1-8.

[6] Hu S, Ma X, Zhou W. Condensation heat transfer of ethanol-water vapor in a plate heat exchanger. Applied Thermal Engineering 2017;113:1047-55. https://doi.org/10.1016/j.applthermaleng.2016.11.013.

[7] Beér JM. High efficiency electric power generation: The environmental role. Progress in Energy and Combustion Science 2007;33:107-34. https://doi.org/https://doi.org/10.1016/j.pecs.2006.08.002.

[8] Liu Y, Kulacki FA. An experimental study of defrost on treated surfaces: Effect of frost slumping. International Journal of Heat and Mass Transfer 2018;119:880-90. https://doi.org/10.1016/j.jheatmasstransfer.2017.12.018.

[9] Miljkovic N. Development and Characterization of Micro / Nano structured Surfaces for Enhanced Condensation. Massachusetts Institute of Technology, 2013.

[10] Mu C, Pang J, Lu Q, Liu T. Effects of surface topography of material on nucleation site density of dropwise condensation. Chemical Engineering Science 2008;63:874-80. https://doi.org/10.1016/j.ces.2007.10.016.

[11] Rausch MH, Fröba AP, Leipertz A. Dropwise condensation heat transfer on ion implanted aluminum surfaces. International Journal of Heat and Mass Transfer 2008;51:1061-70. https://doi.org/10.1016/j.ijheatmasstransfer.2006.05.047.

[12] Yan J, Yang Y, Hu S, Zhen K, Liu J. Effects of vapor pressure/velocity and concentration on condensation heat transfer for steam-ethanol vapor mixture. Heat and Mass Transfer/Waerme- Und Stoffuebertragung 2007;44:51-60. https://doi.org/10.1007/s00231-006-0216-5.

[13] Tanner DW, Pope D, Potter CJ, West D. Heat transfer in dropwise condensation at low steam pressures in the absence and presence of non-condensable gas. International Journal of Heat and Mass Transfer 1968;11:18190. https://doi.org/10.1016/0017-9310(68)90148-8.

[14] Roudgar M, De Coninck J. Condensation heat transfer coefficient versus wettability. Applied Surface Science 2015;338:15-21. https://doi.org/10.1016/j.apsusc.2015.02.087.

[15] Wilkins DG, Bromley LA, Read SM. Dropwise and filmwise condensation of water vapor on gold. AIChE Journal 1973;19:119-23. https://doi.org/10.1002/aic.690190117.

[16] Chatterjee A, Derby MM, Peles Y, Jensen MK. Condensation heat transfer on patterned surfaces. International Journal of Heat and Mass Transfer 2013;66:889-97. https://doi.org/10.1016/j.ijheatmasstransfer.2013.07.077.

[17] Zaitsev DV, Batishcheva KA, Kuznetsov GV, Orlova EG. Prediction of water droplet behavior on aluminum alloy surfaces modified by nanosecond laser pulses. Surface and Coatings Technology 2020;399:126206. https://doi.org/10.1016/j.surfcoat.2020.126206.

[18] Zhao Q, Burnside BM. DROPWISE CONDENSATION OF STEAM ON ION IMPLANTED CONDENSER SURFACES. Heat Recovery Systems and CHP 1994;14:525-34.

[19] Zarei S, Talesh Bahrami HR, Saffari H. Effects of geometry and dimension of micro/nano-structures on the heat transfer in dropwise condensation: A theoretical study. Applied Thermal Engineering 2018;137:440-50. https://doi.org/10.1016/j.applthermaleng.2018.04.003.

[20] Yang K-S, Lu W, Wu Y-L. Visualization of Patterned Modified Surfaces in Condensation and Frosting States. Energies 2019;12:4471. https://doi.org/10.3390/en12234471.

[21] Liu M, Li J, Zhou X, Li J, Feng S, Cheng Y, et al. Inhibiting Random Droplet Motion on Hot Surfaces by Engineering Symmetry- Breaking Janus- Mushroom Structure. Advanced Materials 2020;32:1907999. https://doi.org/10.1002/adma.201907999.

[22] Orejon D, Shardt O, Gunda NSK, Ikuta T, Takahashi K, Takata Y, et al. Simultaneous dropwise and filmwise condensation on hydrophilic microstructured surfaces. International Journal of Heat and Mass Transfer 2017;114:187-97. https://doi.org/10.1016/j.ijheatmasstransfer.2017.06.023. 
[23] Schmidt E, Schurig W, Sellschopp W. Versuche über die Kondensation von Wasserdampf in Film- und Tropfenform. Technische Mechanik Und Thermodynamik 1930;1:53-63. https://doi.org/10.1007/BF02641051.

[24] Baojin Q, Li Z, Hong X, Yan S. Experimental study on condensation heat transfer of steam on vertical titanium plates with different surface energies. Experimental Thermal and Fluid Science 2011;35:211-8. https://doi.org/10.1016/j.expthermflusci.2010.09.003.

[25] Acatay K, Simsek E, Ow-Yang C, Menceloglu YZ. Tunable, superhydrophobically stable polymeric surfaces by electrospinning. Angewandte Chemie - International Edition 2004;43:5210-3. https://doi.org/10.1002/anie.200461092.

[26] Koch C, Kraft K, Leipertz A. Parameter Study on the Performance of Dropwise Condensation. International Journal of Thermal Sciences 1998;37:539-48.

[27] Worthington AM. A second paper on the forms assumed by drops of liquids falling vertically on a horizontal plate. Proc. R. Soc. London, 25, 1876, p. 498-503.

[28] Furuta T, Nakajima A, Sakai M, Isobe T, Kameshima Y, Okada K. Evaporation and sliding of water droplets on fluoroalkylsilane coatings with nanoscale roughness. Langmuir 2009;25:5417-20. https://doi.org/10.1021/la8040665.

[29] Hong BS, Han JH, Kim ST, Cho YJ, Park MS, Dolukhanyan T, et al. Endurable water-repellent glass for automobiles. Thin Solid Films 1999;351:274-8. https://doi.org/10.1016/S0040-6090(98)01794-5.

[30] Yuvaraj R, Senthkil K. Study of droplet dynamics and condensation heat transfer on superhydrophobic copper surface. Thermal Science 2021;25:653-64. https://doi.org/10.2298/TSCI190126089Y.

[31] Kobayashi H, Owen MJ. Surface Tension of Poly[(3,3,4,4,5,5,6,6,6-nonafluorohexyl)-methylsiloxane]. Macromolecules 1990;23:4929-33. https://doi.org/10.1021/ma00225a008.

[32] Betz AR, Jenkins J, Kim CJ, Attinger D. Boiling heat transfer on superhydrophilic, superhydrophobic, and superbiphilic surfaces. International Journal of Heat and Mass Transfer 2013;57:733-41. https://doi.org/10.1016/j.jheatmasstransfer.2012.10.080.

[33] Sharma CS, Stamatopoulos C, Suter R, von Rohr PR, Poulikakos D. Rationally 3D-Textured Copper Surfaces for Laplace Pressure Imbalance-Induced Enhancement in Dropwise Condensation. ACS Applied Materials \& Interfaces 2018;10:29127-35. https://doi.org/10.1021/acsami.8b09067.

[34] Balekjian G, Katz DL. Heat transfer from superheated vapors to a horizontal tube. AIChE Journal 1958;4:438. https://doi.org/10.1002/aic.690040109.

[35] Webb RL. Convective condensation of superheated vapor. Journal of Heat Transfer 1998;120:418-21. https://doi.org/10.1115/1.2824266.

[36] Chen K, Sun T. Effects of microstructure design on aluminum surface hydrophobic and ice-retarding properties. Asia-Pacific Journal of Chemical Engineering 2017;12:307-12. https://doi.org/10.1002/apj.2073.

[37] Cengel Y, Ghajar A. Heat and mass transfer. Heat and Mass Transfer: Fundamentals and Applications. Fifth Ed., The McGraw-Hill Companies; 2015.

[38] Nusselt W. Die Oberflächenkondensation des Wasserdampfes. Zeitschrift Des Vereins Deutscher Ingenieure 1916;60:541-546.

[39] McCormick JL, Baer E. On the mechanism of heat transfer in dropwise condensation. Journal of Colloid Science 1963;18:208-16. https://doi.org/10.1016/0095-8522(63)90012-6.

[40] Sikarwar BS, Khandekar S, Agrawal S, Kumar S, Muralidhar K. Dropwise condensation studies on multiple scales. Heat Transfer Engineering 2012;33:301-41. https://doi.org/10.1080/01457632.2012.611463.

[41] Paxson AT, Yagüe JL, Gleason KK, Varanasi KK. Stable dropwise condensation for enhancing heat transfer via the initiated chemical vapor deposition (iCVD) of grafted polymer films. Advanced Materials 2014;26:418-23. https://doi.org/10.1002/adma.201303065.

[42] Bi P, Li H, Zhao G, Ran M, Cao L, Guo H, et al. Robust super-hydrophobic coating prepared by electrochemical surface engineering for corrosion protection. Coatings 2019;9. https://doi.org/10.3390/coatings9070452.

[43] Wen R, Lan Z, Peng B, Xu W, Ma X. Droplet dynamics and heat transfer for dropwise condensation at lower and ultra-lower pressure. Applied Thermal Engineering 2015;88:265-73. https://doi.org/10.1016/j.applthermaleng.2014.09.069.

[44] Yamada Y, Takahashi K, Ikuta T, Nishiyama T, Takata Y, Ma W, et al. Tuning Surface Wettability at the Submicron-Scale: Effect of Focused Ion Beam Irradiation on a Self-Assembled Monolayer. Journal of Physical Chemistry C 2016;120:274-80. https://doi.org/10.1021/acs.jpcc.5b09019.

[45] Andrieu C, Beysens DA, Nikolayev VS, Pomeau Y. Coalescence of sessile drops. Journal of Fluid Mechanics 2002;453:427-38. https://doi.org/DOI: 10.1017/S0022112001007121. 
[46] Marto PJ, Looney DJ, Rose JW, Wanniarachchi AS. Evaluation of organic coatings for the promotion of dropwise condensation of steam. International Journal of Heat and Mass Transfer 1986;29:1109-17. https://doi.org/https://doi.org/10.1016/0017-9310(86)90142-0.

[47] Koch G, Zhang DC, Leipertz A. Condensation of steam on the surface of hard coated copper discs. Heat and Mass Transfer 1997;32:149-56. https://doi.org/10.1007/s002310050105.

[48] Budakli M, Salem TK, Arik M, Donmez B, Menceloglu Y. Effect of Polymer Coating on Vapor Condensation Heat Transfer. Journal of Heat Transfer 2020;142. https://doi.org/10.1115/1.4046300.

[49] Budakli M, Salem TK, Arik M, Dönmez B, Menceloglu Y. An experimental study on the heat transfer and wettability characteristics of micro-structured surfaces during water vapor condensation under different pressure conditions. International Communications in Heat and Mass Transfer 2021;120:105063. https://doi.org/10.1016/j.icheatmasstransfer.2020.105063.

[50] Carey VP. Liquid-Vapor Phase-Change Phenomena: An Introduction to the Thermophysics of Vaporization and Condensation Processes in Heat Transfer Equipment. New York: Taylor and Francis; 2008. https://doi.org/https://lib.ugent.be/catalog/rug01:001430011.

[51] Schrage RW. A Theoretical Study of Interphase Mass Transfer. New York: Columbia University Press; 1953.

[52] Umur A, Griffith P. Mechanism of Dropwise Condensation. Journal of Heat Transfer 1965;87:275-82. https://doi.org/10.1115/1.3689090.

[53] Rohsenow WM. Status of and Problems in Boiling and Condensation Heat Transfer. Pergamon Press; 1972. https://doi.org/10.1016/b978-0-08-017035-0.50007-0.

[54] Miljkovic N, Enright R, Wang EN. Modeling and optimization of superhydrophobic condensation. Journal of Heat Transfer 2013;135. https://doi.org/10.1115/1.4024597.

[55] Cha H, Vahabi H, Wu A, Chavan S, Kim MK, Sett S, et al. Dropwise condensation on solid hydrophilic surfaces. Science Advances 2020;6. https://doi.org/10.1126/sciadv.aax0746. 